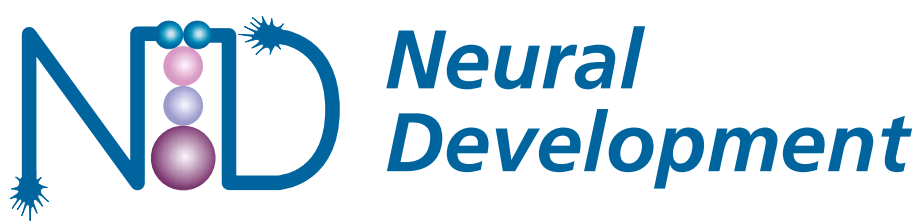

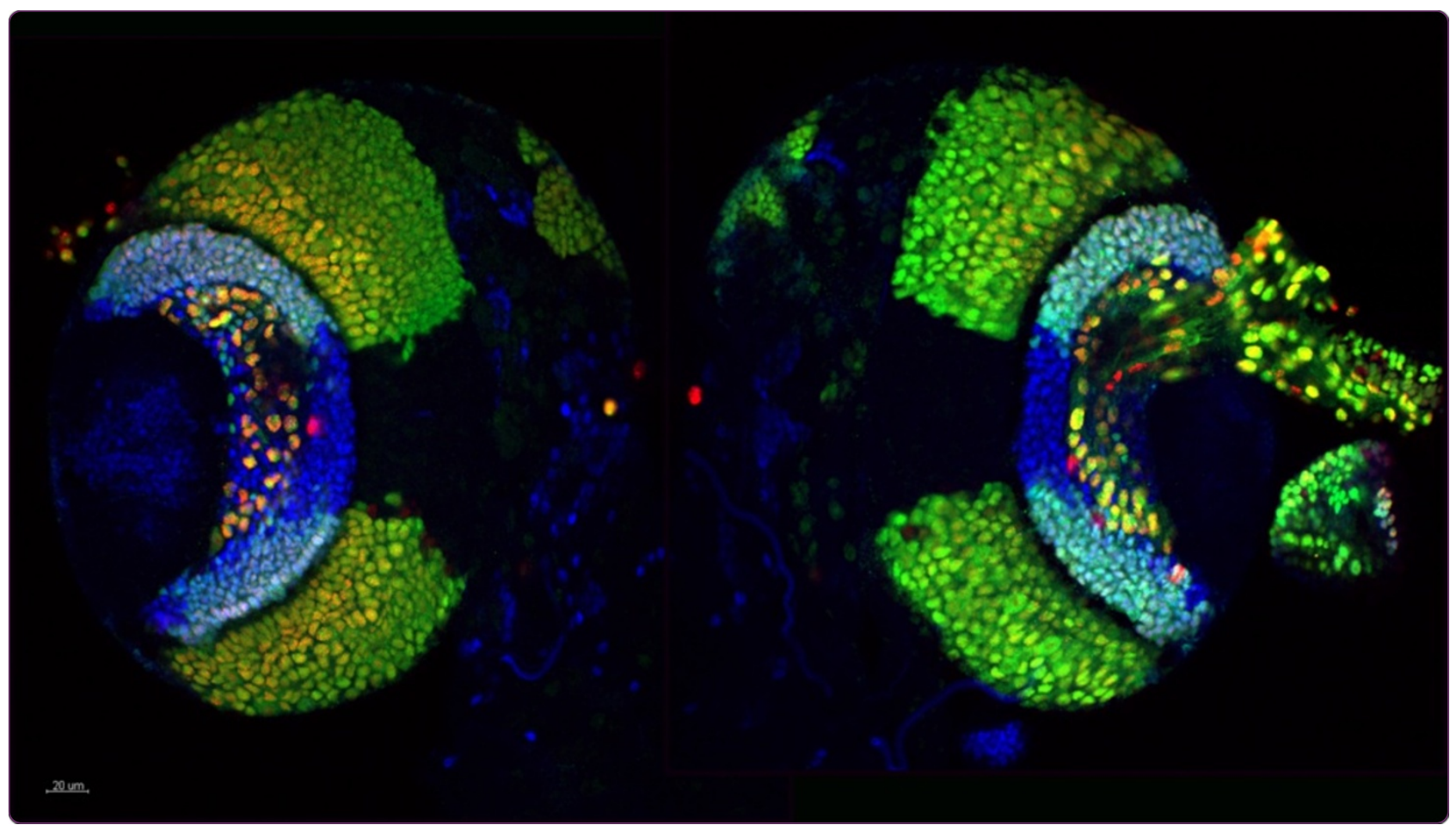

\section{Optix defines a neuroepithelial compartment in the optic lobe of the Drosophila brain}

Gold and Brand 


\title{
Optix defines a neuroepithelial compartment in the optic lobe of the Drosophila brain
}

Katrina S Gold ${ }^{1,2}$ and Andrea H Brand ${ }^{1 *}$

\begin{abstract}
Background: During early brain development, the organisation of neural progenitors into a neuroepithelial sheet maintains tissue integrity during growth. Neuroepithelial cohesion and patterning is essential for orderly proliferation and neural fate specification. Neuroepithelia are regionalised by the expression of transcription factors and signalling molecules, resulting in the formation of distinct developmental, and ultimately functional, domains.

Results: We have discovered that the Six3/6 family orthologue Optix is an essential regulator of neuroepithelial maintenance and patterning in the Drosophila brain. Six3 and Six6 are required for mammalian eye and forebrain development, and mutations in humans are associated with severe eye and brain malformation. In Drosophila, Optix is expressed in a sharply defined region of the larval optic lobe, and its expression is reciprocal to that of the transcription factor Vsx1. Optix gain- and loss-of-function affects neuroepithelial adhesion, integrity and polarity. We find restricted cell lineage boundaries that correspond to transcription factor expression domains.
\end{abstract}

Conclusion: We propose that the optic lobe is compartmentalised by expression of Optix and Vsx1. Our findings provide insight into the spatial patterning of a complex region of the brain, and suggest an evolutionarily conserved principle of visual system development.

Keywords: Neuroepithelium, Stem cell, Adhesion, Compartment, Optix, Six, Visual system, Brain

\section{Background}

Maintaining the spatial organization of growing tissues represents a fundamental developmental challenge. Growth is essential for organogenesis, but must occur in a highly ordered fashion. One strategy is to organize stem cell or progenitor populations into epithelia, physically constraining the dividing cells [1]. For example, the stem cells that generate epidermal, intestinal and neural tissue form monolayered or pseudostratified epithelia that expand laterally to increase the pool of tissue specific precursor cells [2-4]. Growing epithelia are regionalised by zones of transcription factor and signalling molecule expression, which act in concert to confer specific fates and functions $[5,6]$. This is particularly evident during the development of the nervous system [7-11]. Proliferating tissues must be patterned as they grow, so that morphogenesis proceeds correctly and cells acquire the correct fate wherever they are

\footnotetext{
* Correspondence: a.brand@gurdon.cam.ac.uk

${ }^{1}$ The Gurdon Institute and Department of Physiology, Development \& Neuroscience, University of Cambridge, Tennis Court Road, Cambridge CB2 $1 \mathrm{QN}$, UK

Full list of author information is available at the end of the article
}

located. However the precise molecular chain of events linking regionalisation, cell behaviour and tissue morphogenesis is only beginning to be uncovered.

The vertebrate central nervous system is patterned along its dorsal-ventral, anterior-posterior and mediallateral axes [7-9]. For example, the vertebrate mid- and hindbrain are compartmentalised into lineage-restricted neuroepithelial domains called rhombomeres [12,13]. The formation of compartments ensures that cells in neighbouring rhombomeres segregate away from each other to maintain tissue boundaries. The embryonic neocortex is 'arealized', meaning that it is partitioned into regions with distinct functions, architectural organisation and gene expression signatures (reviewed in $[14,15]$ ). Each territory is subdivided by the action of signalling centres and transcription factor expression. This process of regionalisation is essential for the correct specification of neural precursors at different positions, and ultimately the formation of distinct neuronal subpopulations.

During the early development of the nervous system, proliferating neural progenitors are organised into a 
neuroepithelial sheet [4,16-18]. Neuroepithelial cells exhibit classical epithelial characteristics, such as apico-basal polarity and adherens junctions, and give rise to exclusively neural lineages. A comparison of the formation of the mammalian forebrain and the Drosophila optic lobe illustrates the striking evolutionary conservation of this mode of neural development [18-20]. In both systems, an early pool of symmetrically dividing neuroepithelial cells proliferates rapidly to expand neural progenitor numbers. Over time, there is a shift from neural stem cell expansion through symmetric division to asymmetric stem cell selfrenewal, which promotes the maintenance of stem cell numbers and the production of differentiated neuronal and glial progeny.

The similarities between invertebrate and vertebrate neural development are not solely architectural. Notch signalling maintains neuroepithelial identity and regulates the balance between stem cell proliferation and differentiation in both the Drosophila optic lobe [21-27] and the mammalian cortex [28-30]. Thus fundamental organisational principles and molecular mechanisms are conserved between vertebrate and invertebrate neural development [19].

Despite the evolutionary conservation of many aspects of neurogenesis $[10,19,31]$, it was not clear whether a process of spatial regionalisation occurs during the formation of the Drosophila optic lobe. Although less complex than the cerebral cortex, the optic lobe still contains enormous cellular diversity. The adult fly brain comprises roughly 150,000 neurons, of which approximately 60,000 belong to the visual system [32]. These neurons form the neural circuitry that receives and processes visual information from photoreceptors in the eye. The numbers, spatial organization and types of neurons produced must be tightly controlled to ensure the formation of functional visual circuits and preserve retinotopy - the spatial mapping of visual information from the retina to the brain [33].

Optic lobe neurons are formed during larval development by two proliferative neuroepithelia known as the inner and outer proliferation centres (IPC and OPC) $[34,35]$. Here we describe a new role for the homeobox gene Optix in regulating the spatial organisation of the OPC. Optix encodes a Six class homeodomain transcription factor with two vertebrate orthologues, Six3 and Six6 [36-38]. Thus far, Optix function has primarily been characterised in the context of Drosophila eye development, as it is a member of the gene regulatory network that coordinates proliferation and differentiation in the developing retina (the Retinal Determination Network; see reviews in [39-42]). Optix misexpression is sufficient to induce ectopic eye formation $[43,44]$, and a recent study has shown that it is required for the progression of the morphogenetic furrow across the developing eye [45]. Work on Optix function during embryogenesis has also demonstrated that it has an important role in head specification and the regionalisation of the embryo [46].

We found that Optix has a striking expression pattern in the larval brain. Optix protein is expressed throughout larval development in a sharply defined segment of the optic lobe neuroepithelium. We observe that the OPC is pre-patterned by transcription factors, and that the sharp boundaries of Optix expression persist over the course of normal growth and Fat-Hippo-mediated overproliferation. Both gain and loss of Optix function induces cell sorting, the disruption of neuroepithelial tissue structure, and the formation of ectopic neuroepithelial rosettes. Furthermore, we find evidence of straight optic lobe lineage boundaries, which are defined by mutually exclusive transcription factor expression. These data have led us to propose a model in which Optix compartmentalises the brain and regulates neuroepithelial maintenance, polarity and survival in the optic lobe.

\section{Results}

The Six family homeodomain transcription factor Optix is expressed in the optic lobe neuroepithelium

We investigated which genes were expressed in the optic lobe neuroepithelium using transcriptome analysis $[21,47]$. This led to the identification of Optix, which was significantly upregulated in neuroepithelial cells compared to optic lobe neuroblasts. We analysed Optix protein expression in the optic lobe and found that it is strikingly enriched in the optic lobe outer proliferation centre. The outer proliferation centre (OPC) is a horseshoe-shaped neuroepithelium, which covers the lateral side of each brain lobe (Figure 1A, 1B). Each neuroepithelial arm gives rise to medulla neuroblasts (NBs) at the medial edge and lamina precursor cells (LPCs) at the lateral edge (Figure 1B). Optix is expressed in a symmetric domain in the two halves of the neuroepithelium (Figure 1C-E). It has a central gap in the anterior-most neuroepithelium (Figure 1D) and a particularly sharp posterior boundary of expression (Figure 1E). Interestingly, this posterior expression boundary abuts the Wingless signalling domain at the tips of the posterior OPC arms (Additional file 1; [48]). Optix protein expression is downregulated at the transition zone, where medial neuroepithelial cells become medulla neuroblasts and start dividing asymmetrically (Additional file 1). We noted Optix expression in other cell types in the brain, including glia and central brain neuroblast lineages (Additional file 2; [49]). These results indicated that Optix could potentially regulate brain development, in addition to its previously characterised role in retinal determination. 

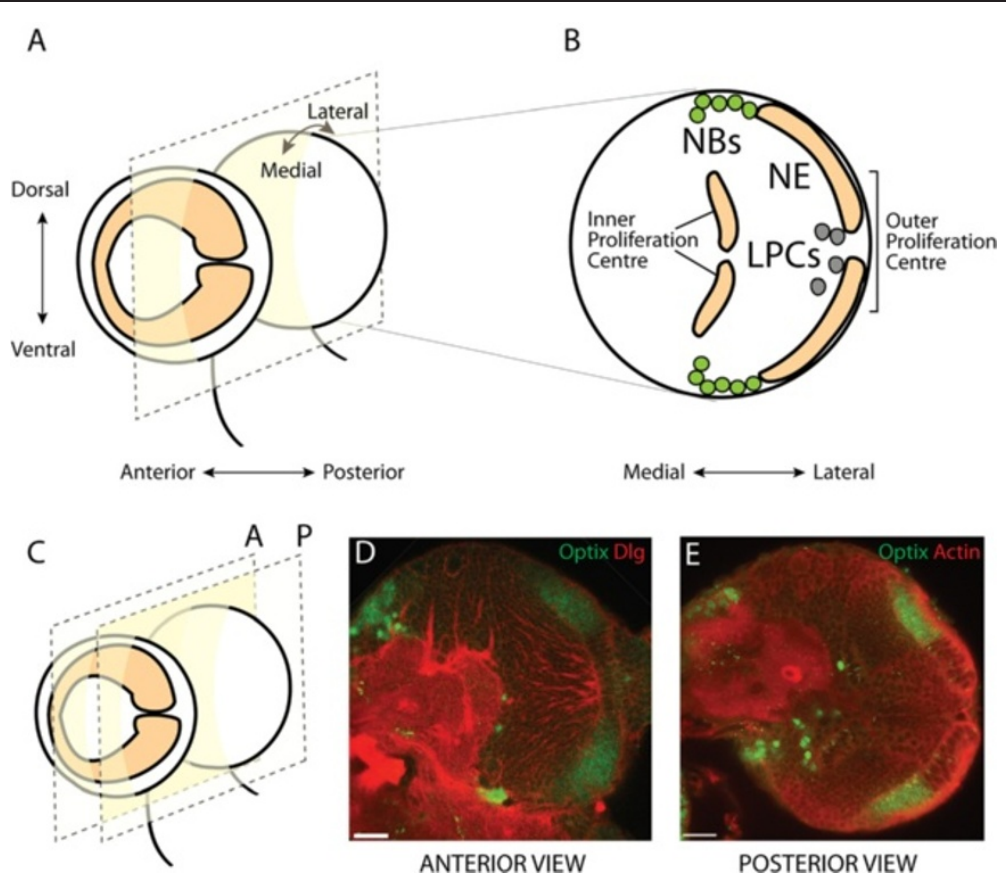

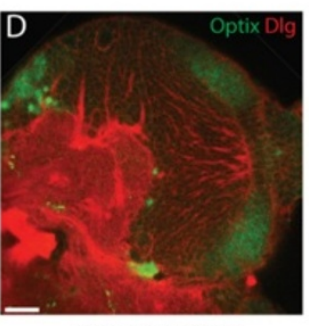

ANTERIOR VIEW

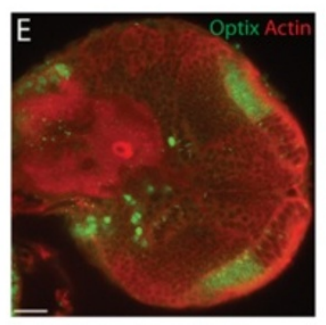

POSTERIOR VIEW

Figure 1 Optix is expressed in half of the optic lobe neuroepithelium. (A) Cartoon of a lateral view of larval third instar brain lobes. The optic lobe outer proliferation centre (OPC) is a horseshoe-shaped neuroepithelium (orange), which covers the lateral side of each brain lobe. A frontal cross-section is indicated by the dotted square. Dorsal-ventral, anterior-posterior and medial-lateral axes indicated by arrows. (B) Cartoon of a posterior frontal cross-section through a brain lobe at mid third instar. The OPC neuroepithelium (NE) generates two kinds of neural precursor: asymmetrically dividing medulla neuroblasts (NBs, green) and lamina precursor cells (LPCs, grey). Incoming retinal axons in the optic nerve enter through the central gap in the neuroepithelium. Medial-lateral axis indicated by arrows. (C) Cartoon of a lateral view from (A) showing the planes of two frontal cross-sections (dotted squares), one anterior (A) and one posterior (P). (D) Anterior confocal cross-section through a brain lobe at mid third instar. Cells are outlined in red by Discs large (Dlg) staining. Optix protein (green) is expressed across the neuroepithelium with a central gap. (E) Posterior confocal cross-section through a brain lobe at mid third instar. Cells are outlined in red by Actin staining (Phalloidin). Optix protein (green) is symmetrically expressed across the neuroepithelium with a sharp boundary.

\section{Optix expression is maintained during neuroepithelial developmental expansion}

In order to determine when Optix expression is established, we analysed Optix expression at different time points during larval development (Figure 2). The optic lobe arises from a small placode of cells in the embryo $[35,50,51]$. During embryogenesis these cells are quiescent, and they begin to proliferate just after larval hatching. The region expands and separates into two neuroepithelia, the outer and inner proliferation centres (OPC and IPC) $[34,52]$. We detect Optix expression in the optic lobe just after larval hatching (Figure 2A). Its expression persists in the same domain (roughly half of the neuroepithelium) as the neuroepithelium expands throughout larval development (Figure 2A-F). Its posterior expression boundary (Figure 1E) remains sharp during neuroepithelial expansion and differentiation. These results demonstrate that Optix expression is established and maintained from the beginning of larval development.

\section{Optix expression defines a neuroepithelial compartment} Developing tissues are frequently subdivided into compartments - groups of cells with a distinct identity, that do not intermix, and which may be lineage-restricted [6,53-59]. Compartment formation ensures that cells specified to different fates sort away from each other. The sharply defined zone of Optix expression in the neuroepithelium, and its early establishment, led us to hypothesise that the neuroepithelium is compartmentalised. In order to test this, we carried out lineage tracing in the neuroepithelium using OptixGAL4 (NP2631GAL4 [60]), which recapitulates the Optix expression pattern in the neuroepithelium (Additional file 3), and G-TRACE ('GAL4 Technique for Real-time And Clonal Expression'; [61]). G-TRACE enables both historical and current GAL4 expression to be visualized. It induces stable, heritably maintained EGFP expression in cells, allowing cell lineages to be mapped, while RFP expression labels cells currently expressing the GAL4 line.

The medulla and lamina are two of the visual processing ganglia in the adult optic lobe. Medulla and lamina neurons both derive from OPC neuroepithelial cells [34]. Lineage tracing analysis revealed that Optix-expressing neuroepithelial cells give rise to a neural lineage that forms much of the medulla cortex and also part of the lamina (Figure 3A-A'). The boundaries of the cell lineages 


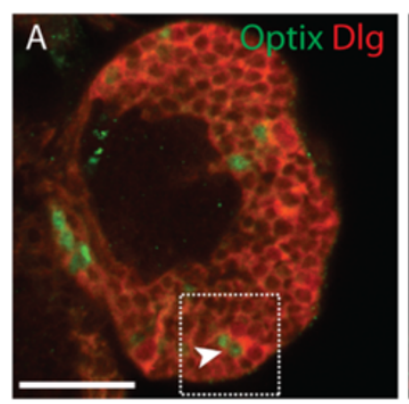

Oh

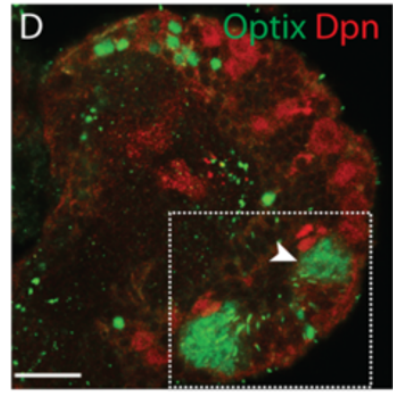

$48 \mathrm{~h}$

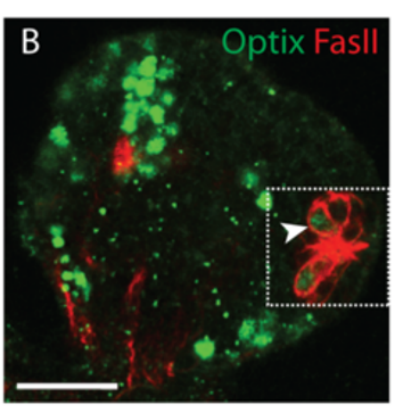

$12 \mathrm{~h}$

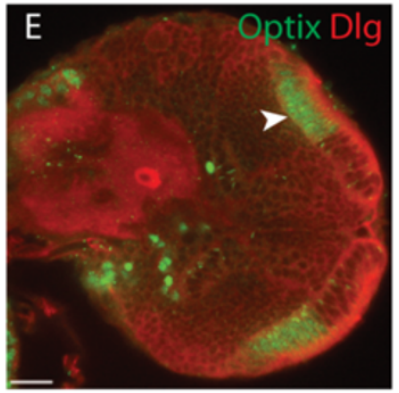

$72 \mathrm{~h}$

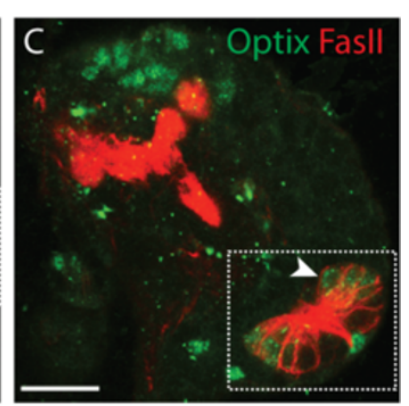

$24 \mathrm{~h}$

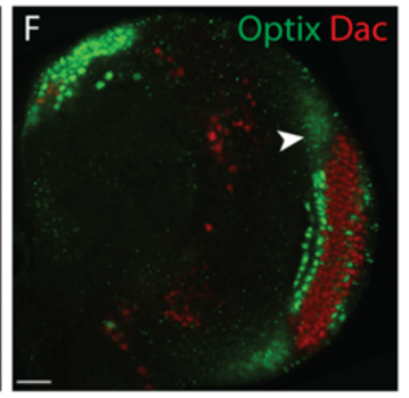

$96 \mathrm{~h}$

Figure 2 Optix expression is maintained throughout optic lobe development. (A-F) We detected Optix protein in the optic lobe from 0 to 96 hours after larval hatching (ALH). Optix expression was detected in the medial neuroepithelium with a sharp boundary of expression throughout neuroepithelial expansion (white arrowhead). Posterior cross-sectional views of the optic lobe are presented throughout. (A-D) The early optic lobe is outlined by dotted white box. (A-C, D) Cells are outlined by Discs large (Dlg) or Fasciclin II (Fas II) staining. (D) Deadpan (Dpn) is expressed in all neuroblasts. (F) Dachshund (Dac) is expressed in lamina precursor cells and lamina neurons. Scale bars: 20 $\mu \mathrm{m}$.

derived from Optix-positive neuroepithelial cells are straight, with a clear central gap (Figure 3A-A', Figure 3B$\left.B^{\prime}\right)$. This gap corresponds to the anterior boundaries of Optix expression (Figure 1D). Interestingly it had previously been reported that the transcription factor Vsx1 is expressed in the central neuroepithelium [62]. Vsx1 is a Drosophila homologue of the homeodomain protein Chx10, which is essential for retinal progenitor cell proliferation and neuronal specification in vertebrates [63]. Vsx1 is expressed in a central population of OPC neuroepithelial cells and a subset of medulla neurons, and is required for neuroepithelial proliferation [62]. We found that Optix and Vsx1 are expressed in complementary neuroepithelial domains throughout optic lobe development (Figure 3B-D"). Vsx1 protein was also observed in medulla neurons, which migrate and mix with neurons derived from the OptixGAL4 lineage. These lineage tracing results, and the complementary expression of Optix and Vsx1, support a model in which the optic lobe neuroepithelium is compartmentalised by transcription factor expression.

\section{Optix expression boundaries persist in conditions of tumorous growth}

The posterior boundary of Optix expression in the neuroepithelium is maintained during the course of normal developmental expansion (Figure 2). Tumour growth can lead to disorderly tissue organisation and the disruption of regional boundaries $[64,65]$, and so we hypothesised that neuroepithelial overgrowth might perturb the Optix expression pattern. We assessed this using a dachsous mutant allele $\left(d s^{05142}\right)$ to disrupt Fat-Hippo signalling (Figure 3). The Fat-Hippo pathway has an essential tumour suppressive role in regulating tissue growth and polarity [66-68], and is known to regulate proliferation and differentiation in the optic lobe neuroepithelium [27,69]. dachsous encodes a large atypical Cadherin which activates the Fat-Hippo signalling cascade through its receptor, Fat [70-73].

$d s^{05142}$ brains are grossly distorted owing to neuroepithelial overproliferation (Figure 4). Despite this, a sharp Optix expression domain is still visible in the optic lobe. This region is larger than in wild type as a consequence of tissue overgrowth, but it still possesses a discrete expression boundary (Figure 4A', B', C'). The persistence of the anterior expression boundary (which is usually 'filled in' by Vsx1 expression) suggests a mechanism is in place to ensure that Optix-expressing cells do not intermingle with their Optix-negative neighbours, even under conditions of extensive overgrowth. This supports our hypothesis that the neuroepithelium is subdivided into compartments defined by transcription factor expression, which are, remarkably, maintained during neoplasia. 


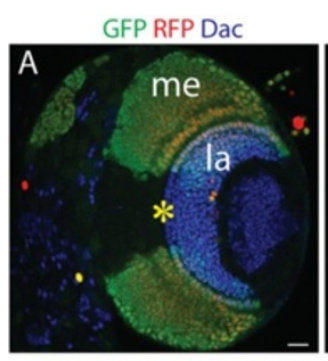

OptixGAL4 lineage Vsx1

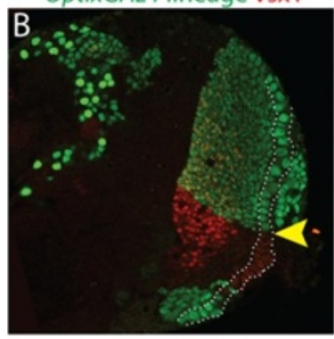

FasIl Optix Vsx1

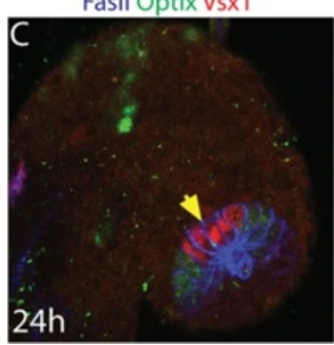

OptixGAL4 lineage

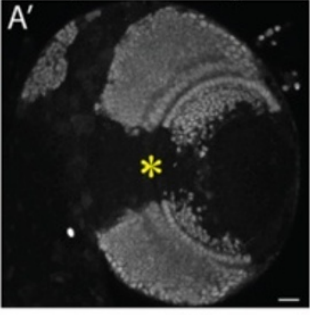

Vsx1

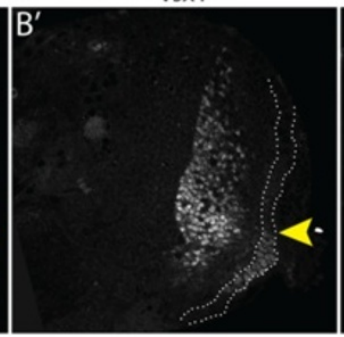

Dlg Optix Vsx1

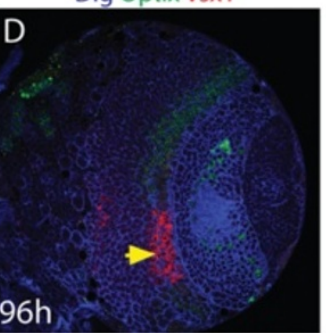

Figure 3 Optix expression defines a restricted neuroepithelial lineage. (A) Anterior view of a late third instar brain lobe. G-TRACE lineage tracing was performed using OptixGAL4. The GFP and RFP-labelled OptixGAL4 lineage forms much of the medulla and part of the lamina neuronal cortices, aside from a clear central gap (yellow star). La, lamina cortex; me, medulla cortex. Lamina neurons are labelled by Dac (blue). (B) Anterior view of a late third instar brain lobe. The outer proliferation centre (OPC) neuroepithelium is outlined by the dashed white line. There is a sharp expression boundary (yellow arrowhead) between the OptixGAL4 lineage derived from Optix-expressing neuroepithelial cells (GFP, green) and Vsx1-expressing neuroepithelial cells (red). (B') Vsx 1 is also expressed in medulla neurons that migrate and intermingle with medulla neurons derived from the OptixGAL4 lineage. (C) Larval brain at 12 hours after larval hatching (ALH). Optix (green) and Vsx1 (red) are expressed in complementary domains. Fas II (blue) labels early neuroepithelial cells. Yellow arrow indicates Vsx1 domain. (D) Anterior view of larval brain at 96 hours ALH. Optix (green) and Vsx1 (red) are expressed in complementary domains. Cells outlined by Dlg (blue). Yellow arrow indicates Vsx1 domain.

\section{Optix represses Vsx1 in the neuroepithelium}

Optix and Vsx1 proteins are expressed in complementary domains throughout optic lobe development, suggesting that they may be mutually exclusive (Figure 3C-D). Therefore, we tested the consequences of Optix misexpression on the Vsx1 domain (Figure 5A-B"). Optix was ectopically expressed in central Vsx1-expressing neuroepithelial cells using VsxGAL4 [62]. This had two clear effects. Firstly, Vsx1 expression was lost from its central neuroepithelial domain (Figure $\left.5 \mathrm{~B}^{\prime \prime}\right)$. The only Vsx1-expressing cells observed in the optic lobe were not neuroepithelial, conforming instead to the wedge-shaped distribution of Vsx1-positive medulla neurons (orange star in Figure 5B"; [62]). Secondly, the morphology of the optic lobe neuroepithelium was distorted compared to wild type brains (Figure 5B'). These results show that ectopic Optix expression in the central neuroepithelial domain disrupts optic lobe patterning. Furthermore, they demonstrate that
Optix is sufficient to repress Vsx1 expression, implying potential negative cross-regulation between Optix and Vsx1. This interaction could contribute to the sharp boundaries of Optix and Vsx1 expression in the anterior OPC neuroepithelium. However we did not observe ectopic Vsx1-positive cells in the Optix neuroepithelial compartment upon loss of Optix expression, either in RNAi knockdown conditions or null mutant clones (data not shown). This suggests that loss of Optix is not sufficient to induce Vsx1 expression within the Optix domain.

\section{Optix is necessary for neuroepithelial maintenance and cell survival}

We analysed the effects of losing Optix function on optic lobe development. Optix null mutants are homozygous lethal and die during late embryogenesis [45]. We induced Optix $^{1}$ null mutant MARCM (Mosaic Analysis with a Repressible Cell Marker) clones within the neuroepithelium 

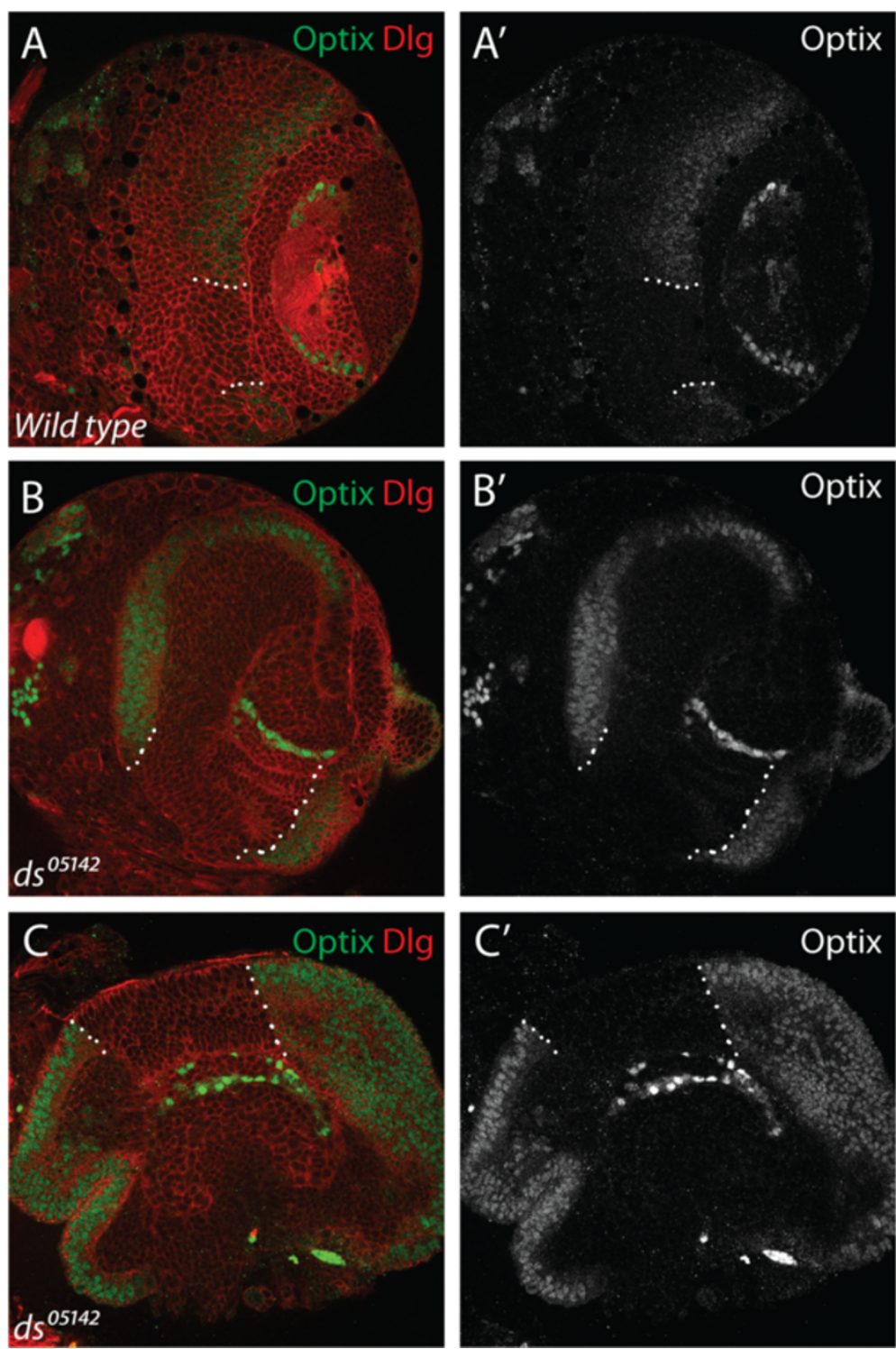

Figure 4 Optix neuroepithelial expression boundaries are maintained during overproliferation. (A) Anterior view of wild type third instar brain lobe shows Optix is expressed in the neuroepithelium with a central gap (indicated by dashed white lines). (B, C) Fat-Hippo signalling disruption in $d s^{05142}$ mutants induces neuroepithelial overproliferation. Optix expression is still absent from the central domain of the anterior outer proliferation centre (OPC) neuroepithelium (dashed lines), and the boundary between Optix-positive and Optix-negative cells is straight.

(A-C) Optix protein is in green, cells are outlined by Dlg staining in red.

(Additional file 4; [45,74]). Few mutant clones were recovered in the Optix-expressing region of the neuroepithelium. The Optix mutant clones that could be identified underwent basal extrusion from the neuroepithelium, indicated by their basal cell bodies and elongated apical stalks (Figure 6B, B"). In contrast, control clones or Optix mutant clones induced where Optix is not expressed appeared wild type (Figure 6A-A", 6C-C"'). Optix mutant clones showed signs of cell death, including fragmentation, which were not evident in control clones (Figure 6B-B") They were positively labelled by TUNEL (Terminal deoxynucleotidyl transferase dUTP Nick End
Labelling) (Additional file 4) and so we concluded that Optix is required for cell survival in a distinct region of the optic lobe.

It was not clear whether the cell death detected in Optix mutant clones was a result of basal extrusion from the neuroepithelium, or whether these cells were extruded because they were undergoing apoptosis. In order to ascertain this, we rescued Optix mutant clones from cell death with baculovirus P35. P35 impairs apical caspase function and inhibits the pro-apoptotic enzyme cascade [75]. Rescuing cell death did not prevent the basal extrusion of Optix mutant clones. Instead, the 


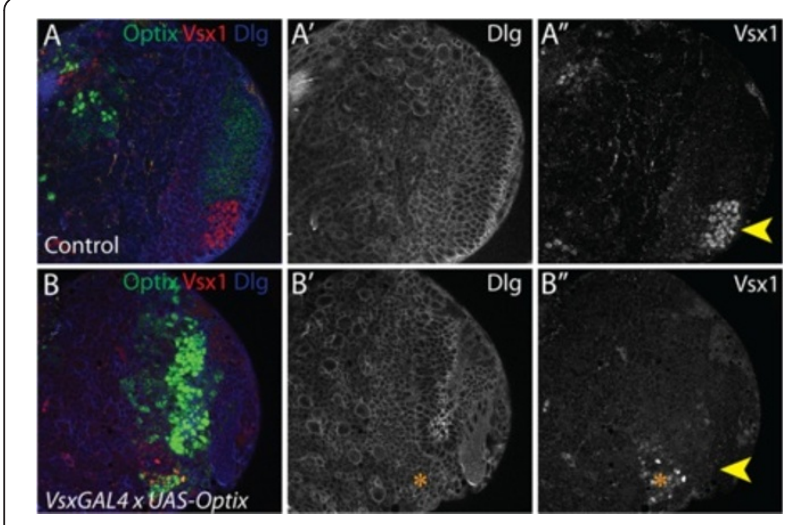

Figure 5 Optix represses Vsx1 expression. (A-B") Anterior views of late third instar larval brains. Optix misexpression in the VsXGAL4 neuroepithelial domain represses Vsx1 expression. Cells outlined by Dlg (blue), Optix protein in green, Vsx1 in red. (B") Vsx1 expression is observed in neurons (orange star) but not in neuroepithelial precursors (yellow arrowhead).

rescued Optix ${ }^{1}$; UASp35 mutant cells sort away from the surrounding wild type neuroepithelium (Figure 7B-C) and form ectopic neuroepithelial rosettes in the underlying differentiated cell layer of the medulla cortex (Figure 7C, 7H, 7I). Apically localised proteins and components of adherens junctions, such as Echinoid [76] and DECadherin [77-81], are clustered in the centre of these rosettes (yellow arrowheads, Figure 7B-C). In contrast, control clones expressing $p 35$ remain within the neuroepithelium and do not form rosettes (Figure 7A,G). These results indicated that extrusion of Optix mutant cells from the neuroepithelium was not a consequence of cell death, as it occurred even when apoptosis was blocked. We therefore concluded that Optix is selectively required for the maintenance of neuroepithelial adhesion and cell survival, within its own domain of expression. This reinforces the notion that Optix expression serves to define a neuroepithelial compartment.

\section{E-Cadherin-mediated adhesion is required for neuroepithelial maintenance}

The extrusion of Optix mutant clones from the neuroepithelium, and their subsequent rosette formation, suggested that Optix might regulate neuroepithelial adhesion. We investigated the effects of disrupting cell adhesion in the neuroepithelium by analysing loss of Drosophila E-Cadherin (DE-Cadherin) function. DECadherin is a crucial component of cellular adherens junctions, and is necessary for maintaining adhesion in a variety of epithelial tissues [77,80-82]. We induced neuroepithelial clones that are mutant for shotgun (shg), which encodes DE-Cadherin [79]. Interestingly, we observed similar cellular responses to loss of both Optix and shg function (compare Figure 7B-C to 7E-F). shg $g^{1}$ mutant clones were basally extruded from the neuroepithelium and formed rosettes beneath the medulla cortex (Figure 7E, 7F). There were also signs of fragmentation and cell death (Figure 7F). This supported the idea that neuroepithelial cells sort away from each other when adhesion is altered, and that Optix regulates optic lobe compartmentalisation by maintaining neuroepithelial adhesion.

Many studies have reported that Notch mutant clones delaminate from the neuroepithelium and transform into ectopic medulla neuroblasts [21-27]. When neuroepithelial cells become neuroblasts, they reorient their spindle poles and dismantle their adherens junctions [52]. Notch mutant clone delamination is likely a consequence of a

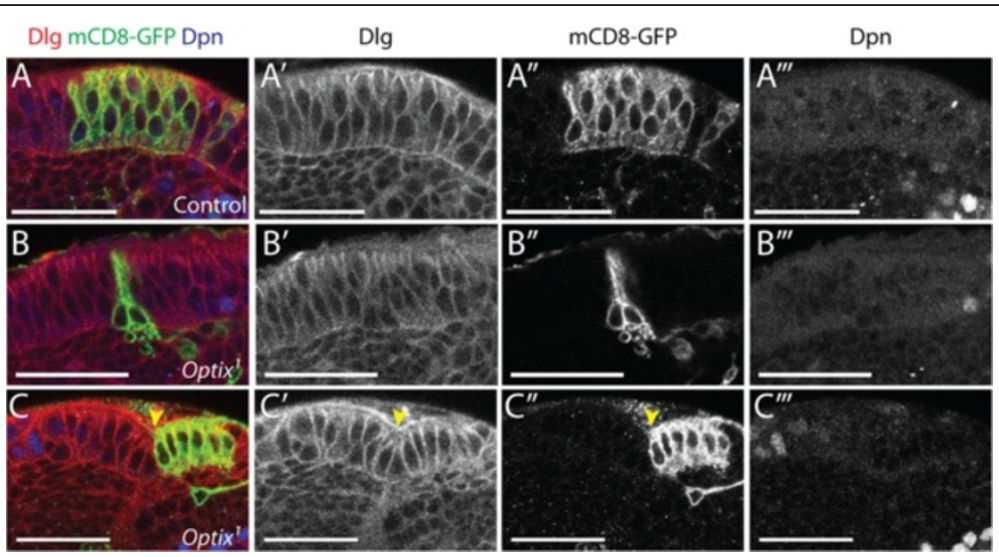

Figure 6 Optix is required for cell survival and adhesion within the neuroepithelium. (A-C'") Control (FRTG13) and Optix null mutant MARCM clones were induced in the neuroepithelium (labelled with mCD8-GFP in green). Cells are outlined by Dlg (red), neuroblasts labelled by Dpn (blue). (A-A"') Wild type clones remain in the neuroepithelium. (B-B"') Optix mutant clones delaminate from the neuroepithelium and show signs of apoptosis, such as cellular fragmentation. (C-C"') Optix mutant clones induced in the lateral neuroepithelium (lateral to the lamina furrow, indicated by yellow arrowhead) do not delaminate or show signs of cell death. Posterior cross-sections are shown in all images. The apico-basal axis of the neuroepithelium is oriented vertically in each image, with the apical surface at the top and the basal surface at the bottom. Scale bars: $30 \mu \mathrm{m}$. 


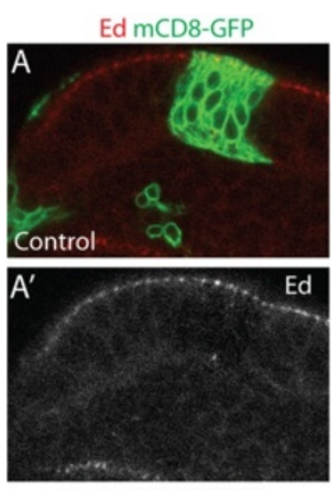

PatJ mCD8-GFP Dlg
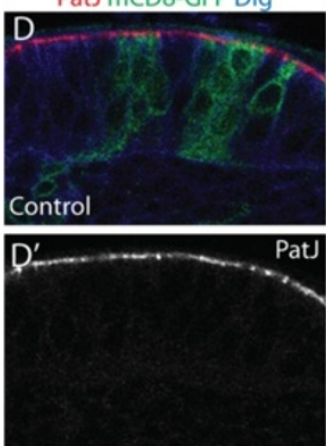

Actin DE-Cad mCD8-GFP

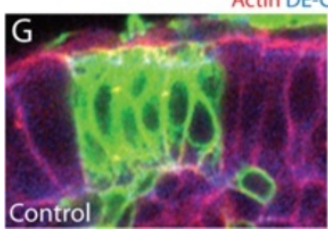

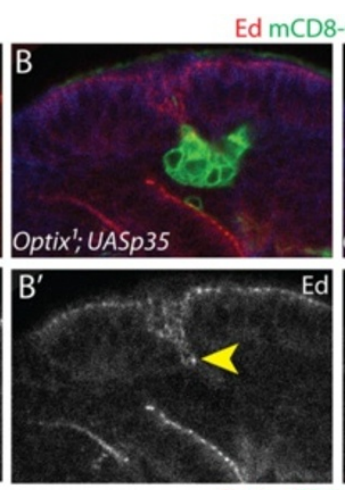

PatJ mCD8-GFP DIg
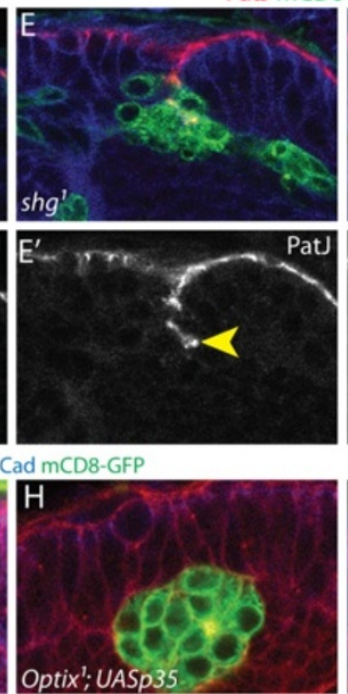
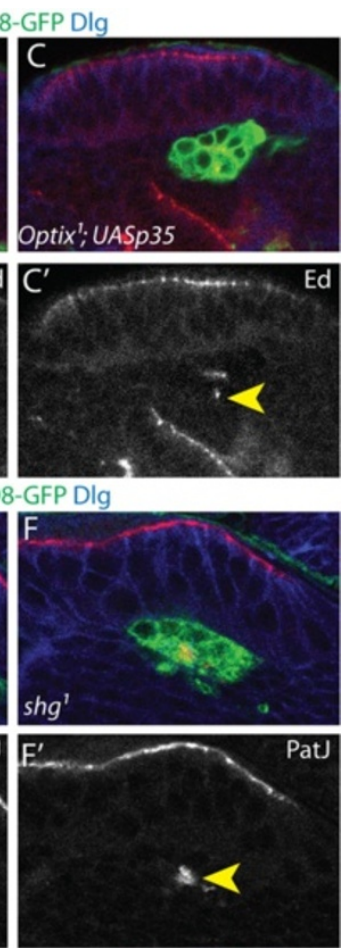

aPKC Dlg mCD8-GFP

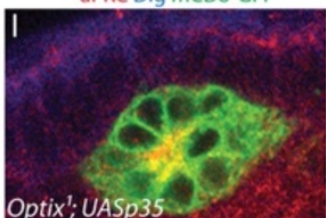

Figure 7 Loss of adhesion leads to ectopic neuroepithelial rosette formation. (A-C') Cell death in Optix null mutant MARCM clones was rescued by expression of p35, which inhibits apoptosis. Clones are labelled with mCD8-GFP (green), Echinoid labels adherens junctions (Ed, red), cells are outlined by Dlg (blue). (A-A') Control clones expressing p35 remain in the neuroepithelium. (B-C') Optix mutant clones expressing p35 form ectopic neuroepithelial rosettes in the underlying medulla cortex. (D-F) Null mutant clones for DE-Cadherin (shg ${ }^{\prime}$ ) delaminate basally from the neuroepithelium to form rosettes below in the underlying medulla cortex (E, F), in contrast to FRTG13 control clones. (D) Clones are labelled with mCD8-GFP (green), PatJ labels adherens junctions (PatJ, red), cells outlined by Dlg (blue). (G-I) Apically localised proteins cluster at the centre of the neuroepithelial rosettes formed by rescued Optix'; UASp35 clones. (G-H) Clones are labelled with mCD8-GFP (green), DE-Cadherin labels adherens junctions (DE-Cad, blue), cells outlined by Phalloidin (F-Actin, red). (I) Clone is labelled with mCD8-GFP (green), cells outlined by Dlg (blue), aPKC is an apically localised protein (aPKC, red). (A-I) Posterior cross-sections are shown in all images. The apico-basal axis of the neuroepithelium is oriented vertically in each image, with the apical surface at the top and the basal surface at the bottom.

loss in adhesion as neuroepithelial cells transform into neuroblasts. However, Wang et al. have reported that a loss of epithelial integrity is not always associated with premature neuroblast formation [24]. Neither Optix ${ }^{1}$ nor shg $g^{l}$ mutant cells showed any signs of differentiation or neurogenesis. In particular, they did not switch on expression of the neuroblast-specific transcription factor Deadpan (Figure 6B"'). This led us to conclude that inducing cells to leave the neuroepithelial niche by modulating adhesion is not sufficient to induce the transition to a neuroblast fate, consistent with Wang et al's study of Notch function [24]. The clustering of Optix and shg mutant neuroepithelial cells into rosettes suggests that these clones have partially lost adhesion but are still able to adhere to each other. Perhaps this retention of adhesion contributes to the maintenance of neuroepithelial character.

Optix misexpression disrupts neuroepithelial architecture Removing Optix from cells surrounded by wild type Optix-expressing neighbours results in basal extrusion and cell sorting. To explore the effects of increased Optix expression on neuroepithelial cell behaviour, we overexpressed Optix in the neuroepithelium. Optix was misexpressed using a temperature-sensitive driver combination either throughout the OPC neuroepithelium (with c855aGAL4) or in the neuroepithelial domain where it is usually expressed (with OptixGAL4). Optix 
misexpression using both drivers induced multi-layering of the OPC neuroepithelium (Figure 8B; Additional file 5), compared to its wild type pseudostratified architecture $[52,83]$. Neuroepithelial cells rounded up and lost their columnar epithelial shape. Apical polarity markers such as Echinoid were lost from these multilayered epithelia (Figure 8B). In some instances Optix misexpression caused the arms of the neuroepithelium to curve and round up on themselves. This resulted in the formation of rosettelike structures, with the apical centres of cells clustered together in the centre, as indicated by Echinoid localisation (Figure 8C). Thus Optix misexpression resulted in a loss of columnar neuroepithelial apico-basal polarity.

We tested the effects of Optix misexpression further by inducing overexpression clones and analysing their behaviour in the neuroepithelium. Optix misexpression

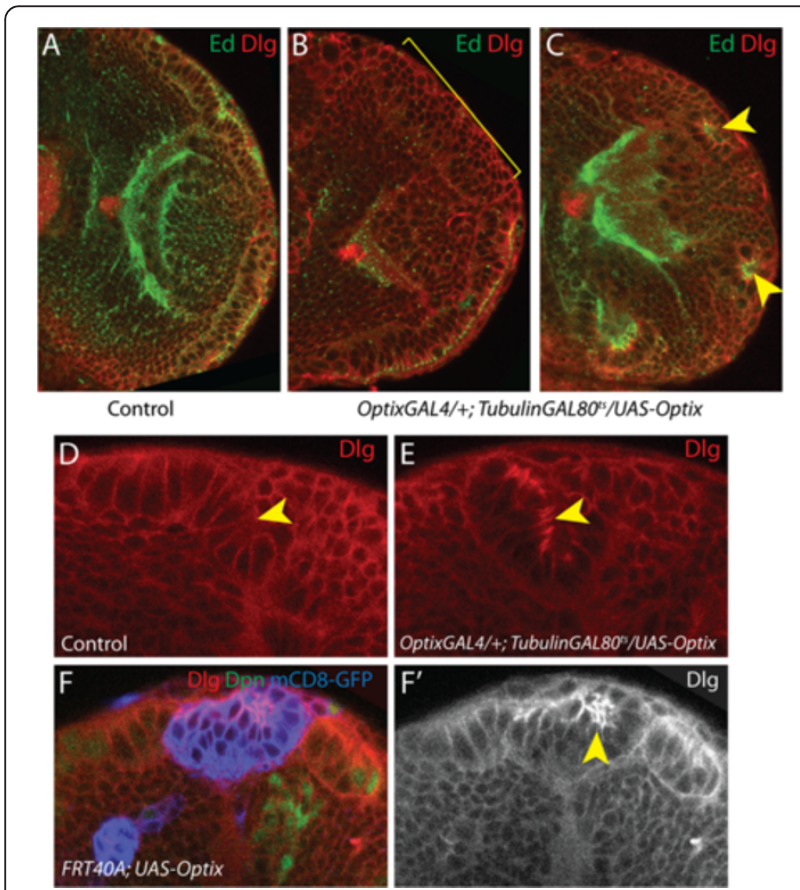

Figure 8 Optix misexpression disrupts neuroepithelial organisation. (A-C) Posterior cross-sections of late third instar brain lobes. Cells are outlined by Dlg (red) and Ed staining labels apical cell surfaces (green), indicating the apico-basal axis of the tissue with respect to the brain. Optix misexpression using OptixGAL4 severely disrupts neuroepithelial architecture. Multilayering of neuroepithelial cells (B) and rosette formation (C, yellow arrowheads) were observed, in contrast to the regular pseudostratified structure of wild type outer proliferation centre (OPC) neuroepithelium (A). (D, E) Optix misexpression alters Dlg (red) levels and localisation. Higher levels of apical Dlg are observed when Optix is misexpressed (yellow arrowhead in $\mathbf{E})$. ( $\mathbf{F}, \mathbf{F}^{\prime}$ ) Optix misexpression clones were induced in the neuroepithelium. These clones form rosettes in which Dlg accumulates apically (yellow arrowhead). Clones labelled with mCD8-GFP (blue), cells stained for Dlg (red) and Dpn (green). (D-F) The apico-basal axis of the neuroepithelium is oriented vertically in each image, with the apical surface at the top and the basal surface at the bottom. clones formed neuroepithelial rosettes (Figure 8F-F'). Rosette formation upon clonal Optix misexpression was also observed in other epithelial tissues, including the imaginal eye and leg discs (Additional file 5C-D"). We noticed that the localisation of the PDZ domain protein Discs large (Dlg) was altered upon Optix misexpression (Figure 8F). Dlg outlines cell cortices in wild type OPC neuroepithelial cells [52]. In Optix misexpressioninduced rosettes, high levels of Dlg were observed towards the centre of the rosette, accumulating at the apical surfaces of cells (Figure 8D-F', Additional file 5). This was also observed when Optix was misexpressed across the neuroepithelium (Figure 8E). Thus Optix misexpression is sufficient to disrupt Dlg localisation and the pseudostratification of the optic lobe neuroepithelium, and we concluded that Optix is a potent regulator of cell polarity and adhesion.

\section{Discussion}

\section{The optic lobe is compartmentalised by transcription} factor expression

The sharply delineated boundaries of Optix expression in the neuroepithelium, and of the lineages derived from this region, suggest that the OPC is compartmentalised. Compartments are classically defined as lineage-restricted populations of cells that do not mix and which may be specified by the expression of a transcription factor or selector gene (reviewed in $[53-55,57,58]$ ). We propose that neural stem cells in the OPC have distinct regional identities conferred by the expression of specific transcription factors (Figure 9). This is supported by the reciprocal expression patterns of Optix and Vsx1, and the fact that that Optix misexpression represses Vsx1 expression, raising the possibility that these transcription factors act as selector genes for distinct neuroepithelial regions. Early Optix and $V s x 1$ expression in the optic lobe could specify 'founder populations' of neuroepithelial cells (Figure 3C), which expand through rounds of symmetric division and ultimately establish the proportions of different OPC regions. The posterior Optix expression boundary is reciprocal to the Wingless signalling domain at the tip of the neuroepithelium. The highly regionalised signalling activity of the Wingless and Dpp pathways also contributes to OPC patterning (Figure 9; [48]).

The cellular mechanisms that control cell sorting and maintain compartment boundaries are not fully understood. Several hypotheses have been proposed, including differential adhesion, differential rates of proliferation, and physical barriers between compartments formed by localised actomyosin cables [58]. In the embryonic mouse forebrain, Cadherin6 and R-Cadherin play an important role in maintaining the compartment boundary between progenitors that form the cerebral cortex and the striatum [84]. Loss of either Optix or DE-Cadherin function 
A

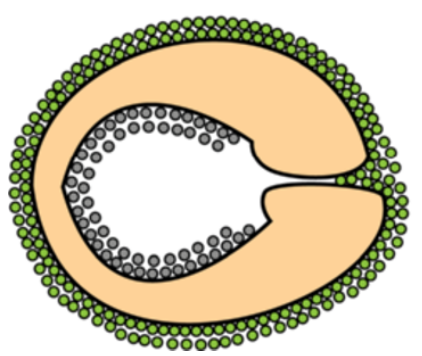

B

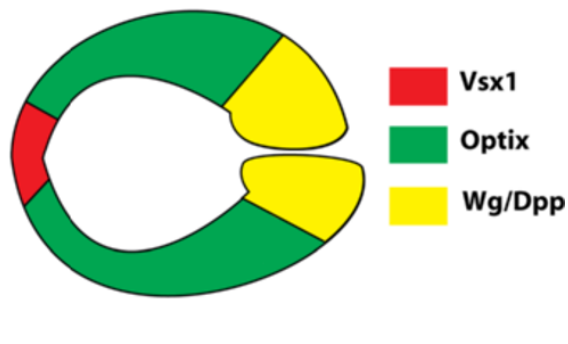

Figure 9 Model for regional neuroepithelial compartments in the optic lobe. (A) Lateral view of the outer proliferation centre (OPC) neuroepithelium (orange), which generates both medulla neuroblasts (green) and lamina precursor cells (grey). (B) The same lateral view of the neuroepithelium, colour coded by the regionalised expression of transcription factors and signalling pathways. Vsx1 (red) is expressed in a central neuroepithelial domain; Optix (green) is expressed in a symmetrical domain on either side. Wingless signalling is active at the tips of the OPC, and activates the Dpp pathway in turn [48].

induces basal extrusion from the neuroepithelium and the formation of neuroepithelial rosettes in the medulla cortex. This phenotypic similarity suggests that Optix regulates intercellular adhesion. A number of Cadherins and other cell adhesion molecules have enriched expression in the OPC neuroepithelium $[21,47,85]$. However, no adhesion molecules have been identified that are regulated by Optix, nor that are expressed in a similarly restricted pattern across the OPC. It is possible that Optix regulates the transcription or post-transcriptional modification of cell adhesion molecules indirectly through other target genes.

Loss and gain of Optix function lead to altered neuroepithelial polarity and, in some cases, the formation of rosettes, suggesting that Optix expression levels must be tightly regulated. Observations of cell sorting upon changes in Optix expression provide further evidence of tissue compartmentalisation in the optic lobe. This behaviour is reminiscent of the cell sorting phenotypes seen when cells are incorrectly specified within a tissue compartment, for example in the Drosophila wing imaginal disc. The wing disc is divided into anterior and posterior compartments, and expression of the transcription factor Engrailed confers posterior compartment identity [86-89]. Engrailed mutant clones induced in the posterior compartment sort away from their neighbours, moving across the compartment boundary into the anterior domain. Optix-expressing cells did not mix with Optix-negative cells even in conditions of hyperplastic overgrowth in dachsous mutant brains, suggesting that mechanisms are in place to prevent the intermingling of these neuroepithelial populations.

\section{Spatial and temporal patterning of the neuroepithelium regulates visual system formation}

Retinotopy - the mapping of visual inputs from the retina to the brain in order to preserve spatial information - is the essential overarching principal of visual system development and organisation. The adult optic lobe contains an estimated 60,000 neurons [32], of which there are at least 70 different subtypes [90,91]. A system of spatio-temporal patterning must be at work in neural progenitors to ensure the production of correctly specified neurons at the right time and place. Indeed two groups recently identified a temporal cascade that patterns neural fates in the optic lobe [92,93]. Optic lobe medulla neuroblasts express a sequence of transcription factors as they age. This clock mechanism specifies neuronal fates in a birth order-dependent manner, in a similar manner to the temporal cascade at work in embryonic neuroblasts [94-106]. Although the transcription factor code itself is different, the same biological mechanism is employed to generate cell fate diversity in both systems (reviewed in [107]).

The OPC neuroepithelium is regionalised by the expression of the transcription factors Optix and Vsx1, in addition to Wingless and Dpp activity (Figure 9). These regional inputs may specify medulla neuroblast fates, and could be combined with the temporal transcription factor cascade to generate diverse neuronal subtypes in the medulla. It is evident that the OPC is regionalised from early larval development (Figure 2, Figure 3C). Signalling centres in the larval neuroepithelium could induce or maintain transcription factor expression, and hence establish compartment boundaries. Indeed there are many candidate pathways which are active in the OPC, including Dpp, Wingless, Fat-Hippo, Notch, EGFR and JAK/STAT $[21-27,69,108-110]$. It remains to be determined how these different inputs are integrated to regulate neural stem cell fates in the optic lobe.

\section{Optix/Six3/6 has a conserved role in neural development}

Neural stem cells are organised into neuroepithelia in most developing nervous systems. These tissues constrain neural precursors architecturally, influencing how they divide and providing a field of cells for molecular 
patterning. Our findings demonstrate a critical role for Optix in regulating neuroepithelial organisation, adhesion and patterning during optic lobe development. We have shown that Optix is essential for cell survival and adhesion in the OPC neuroepithelium, and that ectopic Optix expression perturbs neuroepithelial organisation. These results further our understanding of how Optix regulates visual system development in the Drosophila brain as well as the eye, and they indicate that early neuroepithelial compartmentalisation is a crucial strategy for the development of the optic lobe.

Our findings have direct implications for vertebrate neural development. Optix and its orthologues, Six3 and Six6, encode Six family homeodomain transcription factors that have highly conserved roles in neuroepithelial patterning and regionalisation. Six3 serves as a marker of anterior regional identity across the three major bilaterian clades [111-121]. Six3 and Six6 are crucial for vertebrate eye and forebrain development (reviewed in [122]). Six6 knockout mice exhibit retinal and pituitary hypoplasia [123] and Six3 mutant mice lack most of the forebrain [124]. Further, Six3/6 mutations in humans are associated with a number of severe eye and brain defects including micropthalmia (small eyes), anopthalmia (absence of one or both eyes), pituitary defects and holoprosencephaly (failure of the forebrain to separate into two hemispheres) [125-135].

The important roles Six 3 and Six6 play in mammalian retinal and forebrain development, together with evidence of compartmentalisation in the vertebrate brain [84], suggest that the mechanisms underlying visual system development and neuroepithelial patterning are highly conserved from invertebrates to vertebrates. Further investigation into how Optix controls neuroepithelial development may enhance our understanding of Six3/6-associated congenital brain malformation, providing a genetically tractable model for studying visual system development at the cellular and molecular level.

\section{Conclusions}

Here we show that neuroepithelial progenitors of the Drosophila optic lobe OPC are spatially patterned by the expression of two highly conserved transcription factors: Vsx1 and Optix. Optix defines a neuroepithelial compartment, with a territory of expression that persists throughout physiological growth and Fat-Hippo pathwayinduced overproliferation. Like other developing epithelia, such as the wing imaginal disc, this region of the brain uses compartmentalisation as a mechanism for tissue organisation. Optix is required for neuroepithelial cell survival and adhesion, and its loss results in cell sorting and ectopic neuroepithelial rosettes. Optix misexpression is sufficient to repress Vsx1 expression and induce epithelial multilayering, disrupting neuroepithelial architecture.
The Optix orthologues Six 3 and Six 6 play a critical role in vertebrate eye and brain development, suggesting that the spatial patterning of the visual system may be conserved from invertebrates to vertebrates.

\section{Methods}

\section{Fly lines and staging}

Flies were raised on standard cornmeal medium at $25^{\circ} \mathrm{C}$ or at room temperature (within a range of 21 to $25^{\circ} \mathrm{C}$ ). OregonRS flies were used as wild type controls, unless stated otherwise. Temperature shift experiments were carried out by shifting flies from a permissive temperature of $18^{\circ} \mathrm{C}$ to a non-permissive temperature of $29^{\circ} \mathrm{C}$. Larvae were reared at the required temperature to the desired stage, based on size and time after hatching: just hatched or early first instar (24 to 28 hours after egg laying), first instar ( 0 to 23 hours after larval hatching, ALH), second instar (23 to 46 hours ALH), mid third instar (69 to $75 \mathrm{ALH}$ ) or late third instar (93 to 99 hours ALH).

The following transgenic fly lines were used: $w$; c855aGAL4; tubGAL80 ${ }^{\text {ts }}[52,136,137]$, w; NP2631; tub$G A L 80^{t s}$ [60], InscuteableGAL4 (GAL4 $\left.{ }^{1407}\right)$ [138], yw; ; UAS-Optix (gift from J Kumar; [44]), w; Optix ${ }^{1} / C y O$ (gift from R Chen; [45]), yw hs-FLP; FRT40A, tubGAL80 ${ }^{L L 10} / C y O, A c t G F P J M R 1 ;$ tubGAL4 ${ }^{L L 7}$,UASmCD8:: GFP $P^{L L 6} / T M 6 B, \quad w ; \quad F R T 40 A / C y O ; \quad T M 6 B / M K R S, \quad y w$ hs-FLP; FRTG13,tubGAL80/CyO,ActGFP; tubGAL4,UAS$m C D 8:: G F P / T M 6 B$ (all gifts from B Bello), w; FRT40A/ CyO; UAS-Optix/TM6B, w; FRTG13/SM6a (Bloomington 1958), w; ;UAS-p35 (Bloomington 5073), w; FRTG13/ CyO; UAS-p35, w; FRTG13,Optix ; UAS-p35/TM6B, w; ; UAS-RFP,UAS-flp,Ubi-p63E FRT > STOP > FRT EGFP [61] (Bloomington 28281), w; FRTG13 shg ${ }^{1}$ bw sp/CyO,ftz-lacZ [139], $d s^{05142} / C y O$ (Bloomington 11394), w,VsxGAL4; tub$G A L 80^{t s} / C y O$ (gift from C Desplan; [62]), yw hs-FLP; sp/ CyO; WingfulGAL4/TM6B [140], w; dppGAL4 [141].

\section{Genetic crosses}

Mutant and misexpression clones of cells were induced using the MARCM system [74]. MARCM clones were induced at 12 to 24 hours ALH by heat shocking larvae on fly food plates. The following regime was used: $5 \mathrm{mi}-$ nutes at $37^{\circ} \mathrm{C}, 5$ minutes at room temperature, 15 to 30 minutes at $37^{\circ} \mathrm{C}$. The exact length of the heat shock depended on the MARCM clone induction line being used. Clones were analysed at 72 to 96 hours ALH. For Optix misexpression experiments, embryos of the genotype $w$; tubGAL80 ${ }^{t s} /+$; c855aGAL4/UAS-optix and $w$; OptixGAL4/tubGAL8O ${ }^{\text {ts }}$; UAS-Optix/+were collected at $18^{\circ} \mathrm{C}$ and shifted to $29^{\circ} \mathrm{C}$ between 24 and 48 hours ALH to induce overexpression. Brains were dissected between 72 and 96 hours ALH. For G-TRACE lineage tracing experiments, embryos of the genotype w; OptixGAL4/+; 
UAS-RFP, UAS-flp, Ubi-p63E FRT > STOP > FRT EGFP were collected and raised at $25^{\circ} \mathrm{C}$, and brains were dissected at 96 hours ALH.

\section{Immunohistochemistry}

Larval brains were dissected in PBS and fixed for $20 \mathrm{mi}-$ nutes at room temperature in $4 \%$ formaldehyde and fixation buffer (PBS, $5 \mathrm{mM} \mathrm{MgCl}, 0.5 \mathrm{mM}$ EGTA). After fixation, brains were rinsed and washed in 0.3\% PBSTriton-X100 (PBT). Samples were blocked in 10\% normal goat serum (NGS) in $0.3 \% \mathrm{PBT}$ at room temperature and incubated with the primary antibody overnight at $4{ }^{\circ} \mathrm{C}$. Brains were then washed in $0.3 \%$ PBT, blocked in $10 \%$ $\mathrm{NGS} / 0.3 \% \mathrm{PBT}$ and incubated with the secondary antibody overnight at $4^{\circ} \mathrm{C}$. After incubation with the secondary antibody, tissues were washed in $0.3 \%$ PBT and cleared at $4^{\circ} \mathrm{C}$ in Vectashield (Vector Laboratories, Burlingame, CA, USA). Brains were mounted in Vectashield.

Primary antibodies used in this study were: mouse anti-Dlg (1:50), mouse anti-Fas II (1:20), mouse antiDachshund (1:100), mouse anti-Eyes absent (1:75), mouse anti-Repo (1:70) (all from the Developmental Studies Hybridoma Bank, University of Iowa), rabbit anti-Optix (1:500, gift from F Pignoni; [142]), guinea pig anti-Dpn (1:1,000; gift from J Skeath), chicken anti-GFP (1:2,000, Abcam, Cambridge, UK), guinea pig anti-dVsx1 (1:750, gift from H Lipshitz; [62]), rabbit anti-Echinoid (1:50; gift from A Jarman; [143]), rabbit anti-PatJ (1:500, gift from W Zhou; [144]), rabbit anti-nPKC (1:500, Santa Cruz Biotechnology, Dallas, TX, USA), rabbit anti-Eyeless (1:300, gift from U Walldorf), rabbit anti-Scribble (1:2,000; gift from C Doe; [145]), rabbit anti-Ph3 (1:100, Upstate Biotechnology, Lake Placid, NY, USA). Fluorescently conjugated secondary antibodies were used at a dilution of 1:200 (Alexa405, Alexa488, Alexa546, Alexa568, Alexa633; Molecular Probes, Eugene, OR, USA). Factin was labeled using Alexa fluorophore-conjugated Phalloidin (Phalloidin-546, 1:300, Molecular Probes). TUNEL staining of larval brains was carried out using the ApopTag Red In Situ Apoptosis Detection Kit (EMD Millipore, Billerica, MA, USA) according to the manufacturer's instructions.

Images were acquired with a Leica TCS SP2 or SP5 confocal microscope (Leica Microsystems, Wetzlar, Germany) and analysed with Imaris (Bitplane, Zurich, Switzerland) or Fiji [146]. Figures and illustrations were assembled using Adobe Photoshop CS3 and Adobe Illustrator CS3 (Adobe Systems, San Jose, CA, USA).

\section{Additional files}

Additional file 1: Regionalised Optix expression in the optic lobe. (A) Wingless signalling is active at the lateral edge of the neuroepithelium (between white arrowheads). Optix expression starts just medially to the edge of the Wingless signalling zone (yellow arrowhead). WingfulGAL4 driving UAS-mCD8GFP is the Wingless reporter used [140]. Scale bars: $20 \mu \mathrm{m}$. (B) Dpp is expressed more medially than Wingless (white arrowheads), and Optix expression begins in the middle of the Dpp signalling zone (yellow arrowhead). (A, B) Scale bars: $40 \mu \mathrm{m}$. Posterior cross-sections through the optic lobe are shown. (C) Optix expression in the medial neuroepithelium is downregulated at the transition zone (white arrowhead), where neuroepithelial cells transform into medulla neuroblasts. Medulla neuroblasts are labelled by Inscuteable GAL4 driving UAS-mCD8GFP (Insc-GAL4, red) and the neuroblast-specific transcription factor Deadpan (blue), and Optix protein is in green.

Additional file 2: Optix is expressed in glia and neuroblast lineages. (A) Optix protein is expressed in optic lobe glial cells, including the epithelial and marginal glia (white arrows). Cells labelled with Phalloidin, which stains F-actin (red), the pan-glial transcription factor Repo (blue) and Optix protein (green). (B) Optix is expressed in central brain neuroblast lineages. It can be seen primarily in Type II neuroblasts (white arrows), and in the differentiating progeny of these cells. It was also visible in approximately 1 Type I neuroblast per brain lobe. Neuroblast lineages are labelled by Inscuteable GAL4 driving UAS-mCD8GFP (green), the neuroblast-specific transcription factor Dpn (blue) is expressed in Type I and II neuroblasts as well as Type II lineage intermediate neural progenitors, and Optix is in red.

Additional file 3: OptixGAL4 recapitulates Optix protein expression. (A-A") Posterior frontal cross-section of the optic lobe. OptixGAL4 driving UAS-MCD8GFP (red) showed a similarly well-defined expression pattern in the neuroepithelium to Optix protein (green). Both protein and the GAL4 line have sharp expression boundaries in the OPC neuroepithelium.

Additional file 4: Optix null mutant clones do not express Optix protein and undergo apoptosis. Description: Optix mutant MARCM clones were induced in the neuroepithelium (labelled with mCD8-GFP in green, Dlg in blue). (A-A') Optix ${ }^{7}$ clones do not stain for Optix protein (red), indicating that they are null mutant clones. (B-B") Optix clones in the neuroepithelium undergo apoptosis. They are basally extruded from the neuroepithelium and stain positively for TUNEL (yellow arrow).

Additional file 5: Optix misexpression induces multilayering and clonal cell sorting. (A-B') Optix misexpression throughout the neuroepithelium (with c855aGAL4) induces multilayering. Neuroepithelial cells take on a more rounded appearance, as opposed to their wild type columnar morphology. Cells are outlined by Dlg (red), neuroblasts stained by Dpn (green) and mitotic cells labelled by phospho-histone-H3 ( $\mathrm{PH} 3$, blue). (C-D") Optix misexpression clones induced in imaginal eye (C) and leg (D) discs form epithelial rosettes. Cells are outlined by Discs large staining (Dlg, red), clones labelled with mCD8-GFP (GFP, green), Optix stained in blue. ( $\left.C^{\prime \prime}\right)$ Upon misexpression, Optix protein levels are very high (yellow arrowhead) compared to endogenous levels (white arrowhead). Misexpression clones sort away from their neighbours, and apical constriction and increased apical accumulation of Dlg protein (white arrowhead in D') is visible. Scale bars: $20 \mu \mathrm{m}$.

\section{Abbreviations}

ALH: after larval hatching; G-TRACE: GAL4 technique for real-time and clonal expression; GFP: green fluorescent protein; IPC: inner proliferation centre; LPC: lamina precursor cells; MARCM: Mosaic Analysis with a Repressible Cell Marker; NB: neuroblast; NE: neuroepithelium; OPC: outer proliferation centre; RFP: red fluorescent protein; TUNEL: Terminal deoxynucleotidyl transferase dUTP Nick End Labelling; PBS: phosphate-buffered saline; PBT: PBS-Triton-X100; NGS: normal goat serum.

\section{Competing interests}

The authors declare that they have no competing interests.

\section{Authors' contributions}

KSG and AHB conceived the study and designed the experiments. KSG conducted the expression analysis, lineage tracing, Optix gain and loss of function studies, and shg loss of function analysis. KSG and AHB wrote the manuscript. Both authors read and approved the final manuscript. 


\section{Acknowledgments}

We thank Chris Doe, Andrew Jarman, Howard Lipshitz, Francesca Pignoni, James Skeath, Uwe Walldorf, Wenke Zhou and the Developmental Studies Hybridoma Bank (University of lowa, USA) for providing antibodies, and Bruno Bello, Nick Brown, Rui Chen, Claude Desplan, Justin Kumar, Daniel St Johnson, the Bloomington Stock Center (USA) and NIG-Fly (Japan) for fly lines. We thank Daniel St Johnston and Dan Bergstralh for helpful discussions, and members of the Brand lab for their feedback. We are grateful to Elizabeth Caygill, Esteban Contreras, Boris Egger and Pauline Spéder for comments on the manuscript. This work was funded by Wellcome Trust Programme grants 068055 and 092545 (to AHB) and a Wellcome Trust PhD Studentship (to KSG). AHB acknowledges core funding to the Gurdon Institute from the Wellcome Trust (092096) and CRUK (C6946/A14492). Neither funding body participated in the design of the study, the collection or analysis of the data, the decision to submit the manuscript for publication, or the writing of the manuscript.

\section{Author details}

'The Gurdon Institute and Department of Physiology, Development \& Neuroscience, University of Cambridge, Tennis Court Road, Cambridge CB2 1QN, UK. ${ }^{2}$ Present address: Department of Cell and Tissue Biology and Eli and Edythe Broad Center of Regeneration Medicine and Stem Cell Research, University of California San Francisco, 35 Medical Center Way, San Francisco, CA 94143-0669, USA.

Received: 7 May 2014 Accepted: 25 June 2014 Published: 29 July 2014

\section{References}

1. McCaffrey LM, Macara IG: Epithelial organization, cell polarity and tumorigenesis. Trends Cell Biol 2011, 21:727-735.

2. Barker $\mathrm{N}$, van de Wetering $\mathrm{M}$, Clevers $\mathrm{H}$ : The intestinal stem cell. Genes Dev 2008, 22:1856-1864.

3. Blanpain C, Fuchs E: Epidermal homeostasis: a balancing act of stem cells in the skin. Nat Rev Mol Cell Biol 2009, 10:207-217.

4. Fish JL, Dehay $C$, Kennedy H, Huttner WB: Making bigger brains-the evolution of neural-progenitor-cell division. J Cell Sci 2008, 121:2783-2793.

5. Mann RS, Morata G: The developmental and molecular biology of genes that subdivide the body of Drosophila. Annu Rev Cell Dev Biol 2000, 16:243-271.

6. Tepass U, Godt D, Winklbauer R: Cell sorting in animal development: signalling and adhesive mechanisms in the formation of tissue boundaries. Curr Opin Genet Dev 2002, 12:572-582.

7. Cavodeassi F, Houart C: Brain regionalization: of signaling centers and boundaries. Dev Neurobiol 2012, 72:218-233.

8. Kiecker $C$, Lumsden $A$ : The role of organizers in patterning the nervous system. Annu Rev Neurosci 2012, 35:347-367.

9. Pasini A, Wilkinson DG: Stabilizing the regionalisation of the developing vertebrate central nervous system. Bioessays 2002, 24:427-438.

10. Reichert $\mathrm{H}$ : Evolutionary conservation of mechanisms for neural regionalization, proliferation and interconnection in brain development. Biol Lett 2009, 5:112-116.

11. Urbach R, Technau GM: Dorsoventral patterning of the brain: a comparative approach. Adv Exp Med Biol 2008, 628:42-56.

12. Fraser S, Keynes R, Lumsden A: Segmentation in the chick embryo hindbrain is defined by cell lineage restrictions. Nature 1990, 344:431-435.

13. Lumsden A: The cellular basis of segmentation in the developing hindbrain. Trends Neurosci 1990, 13:329-335.

14. Alfano C, Studer M: Neocortical arealization: evolution, mechanisms, and open questions. Dev Neurobiol 2013, 73:411-447.

15. O'Leary DD, Chou SJ, Sahara S: Area patterning of the mammalian cortex. Neuron 2007, 56:252-269.

16. Doe CQ: Neural stem cells: balancing self-renewal with differentiation. Development 2008, 135:1575-1587.

17. Egger $B$, Chell JM, Brand AH: Insights into neural stem cell biology from flies. Philos Trans R Soc Lond B Biol Sci 2008, 363:39-56.

18. Götz M, Huttner WB: The cell biology of neurogenesis. Nat Rev Mol Cell Biol 2005, 6:777-788

19. Brand AH, Livesey FJ: Neural stem cell biology in vertebrates and invertebrates: more alike than different? Neuron 2011, 70:719-729.
20. Southall TD, Egger B, Gold KS, Brand AH: Regulation of self-renewal and differentiation in the Drosophila nervous system. Cold Spring Harb Symp Quant Biol 2008, 73:523-528.

21. Egger B, Gold KS, Brand AH: Notch regulates the switch from symmetric to asymmetric neural stem cell division in the Drosophila optic lobe. Development 2010, 137:2981-2987.

22. Ngo KT, Wang J, Junker M, Kriz S, Vo G, Asem B, Olson JM, Banerjee U, Hartenstein V: Concomitant requirement for Notch and Jak/Stat signaling during neuro-epithelial differentiation in the Drosophila optic lobe. Dev Biol 2010, 346:284-295.

23. Orihara-Ono M, Toriya M, Nakao K, Okano H: Downregulation of Notch mediates the seamless transition of individual Drosophila neuroepithelial progenitors into optic medullar neuroblasts during prolonged G1. Dev Biol 2011, 351:163-175.

24. Wang W, Liu W, Wang Y, Zhou L, Tang X, Luo H: Notch signaling regulates neuroepithelial stem cell maintenance and neuroblast formation in Drosophila optic lobe development. Dev Biol 2011, 350:414-428.

25. Weng M, Haenfler JM, Lee CY: Changes in Notch signaling coordinates maintenance and differentiation of the Drosophila larval optic lobe neuroepithelia. Dev Neurobiol 2012, 72:1376-1390.

26. Yasugi T, Sugie A, Umetsu D, Tabata T: Coordinated sequential action of EGFR and Notch signaling pathways regulates proneural wave progression in the Drosophila optic lobe. Development 2010, 137:3193-3203.

27. Reddy BV, Rauskolb C, Irvine KD: Influence of fat-hippo and notch signaling on the proliferation and differentiation of Drosophila optic neuroepithelia. Development 2010, 137:2397-2408.

28. Gaiano N, Nye JS, Fishell G: Radial glial identity is promoted by Notch1 signaling in the murine forebrain. Neuron 2000, 26:395-404.

29. Kamakura S, Oishi K, Yoshimatsu T, Nakafuku M, Masuyama N, Gotoh Y: Hes binding to STAT3 mediates crosstalk between Notch and JAK-STAT signalling. Nat Cell Biol 2004, 6:547-554.

30. Yoon K, Gaiano N: Notch signaling in the mammalian central nervous system: insights from mouse mutants. Nat Neurosci 2005, 8:709-715.

31. Doe CQ, Fuerstenberg S, Peng CY: Neural stem cells: from fly to vertebrates. J Neurobiol 1998, 36:111-127.

32. Morante J, Desplan C: Building a projection map for photoreceptor neurons in the Drosophila optic lobes. Semin Cell Dev Biol 2004, 15:137-143.

33. Sato M, Suzuki T, Nakai Y: Waves of differentiation in the fly visual system. Dev Biol 2013, 380:1-11.

34. Hofbauer A, Campos-Ortega JA: Proliferation pattern and early differentiation of the optic lobes in Drosophila melanogaster. Dev Genes Evol 1990, 198:264-274.

35. Meinertzhagen IA, Hanson TE: The development of the optic lobe. In The development of Drosophila melanogaster. Edited by Bate M, Martinez Arias A. Cold Spring Harbor, NY: Cold Spring Harbor Laboratory Press; 1993:1363-1491.

36. Kawakami K, Sato S, Ozaki H, Ikeda K: Six family genes - structure and function as transcription factors and their roles in development. Bioessays 2000, 22:616-626.

37. Seo HC, Drivenes $\varnothing$, Ellingsen S, Fjose A: Expression of two zebrafish homologues of the murine Six3 gene demarcates the initial eye primordia. Mech Dev 1998, 73:45-57.

38. Toy J, Yang JM, Leppert GS, Sundin OH: The optx2 homeobox gene is expressed in early precursors of the eye and activates retina-specific genes. Proc Natl Acad Sci U S A 1998, 95:10643-10648.

39. Kumar JP: The molecular circuitry governing retinal determination. Biochim Biophys Acta 2009, 1789:306-314.

40. Kumar JP: My what big eyes you have: how the Drosophila retina grows. Dev Neurobiol 2011, 71:1133-1152.

41. Pappu KS, Mardon G: Genetic control of retinal specification and determination in Drosophila. Int J Dev Biol 2004, 48:913-924.

42. Silver SJ, Rebay I: Signaling circuitries in development: insights from the retinal determination gene network. Development 2005, 132:3-13.

43. Seimiya M, Gehring WJ: The Drosophila homeobox gene optix is capable of inducing ectopic eyes by an eyeless-independent mechanism. Development 2000, 127:1879-1886.

44. Weasner B, Salzer C, Kumar JP: Sine oculis, a member of the SIX family of transcription factors, directs eye formation. Dev Biol 2007, 303:756-771.

45. Li Y, Jiang Y, Chen Y, Karandikar U, Hoffman K, Chattopadhyay A, Mardon G: Chen R: optix functions as a link between the retinal determination network and the dpp pathway to control morphogenetic furrow progression in Drosophila. Dev Biol 2013, 381:50-61. 
46. Coiffier D, Charroux B, Kerridge S: Common functions of central and posterior Hox genes for the repression of head in the trunk of Drosophila. Development 2008, 135:291-300

47. Southall TD, Gold KS, Egger B, Davidson CM, Caygill EE, Marshall OJ, Brand $\mathrm{AH}$ : Cell-type-specific profiling of gene expression and chromatin binding without cell isolation: assaying RNA Pol II occupancy in neural stem cells. Dev Cell 2013, 26:101-112.

48. Kaphingst $K$, Kunes $\mathrm{S}$ : Pattern formation in the visual centers of the Drosophila brain: wingless acts via decapentaplegic to specify the dorsoventral axis. Cell 1994, 78:437-448.

49. Carney TD, Miller MR, Robinson KJ, Bayraktar OA, Osterhout JA, Doe CQ: Functional genomics identifies neural stem cell sub-type expression profiles and genes regulating neuroblast homeostasis. Dev Biol 2011, 361:137-146.

50. Green $P$, Hartenstein $A Y$, Hartenstein V: The embryonic development of the Drosophila visual system. Cell Tissue Res 1993, 273:583-598.

51. Turner FR, Mahowald AP: Scanning electron microscopy of Drosophila melanogaster embryogenesis. III. Formation of the head and caudal segments. Dev Biol 1979, 68:96-109.

52. Egger B, Boone JQ, Stevens NR, Brand AH, Doe CQ: Regulation of spindle orientation and neural stem cell fate in the Drosophila optic lobe. Neural Dev 2007, 2:1

53. Blair SS: Developmental biology: boundary lines. Nature 2003, 424:379-381.

54. Dahmann C, Oates AC, Brand M: Boundary formation and maintenance in tissue development. Nat Rev Genet 2011, 12:43-55.

55. Irvine KD, Rauskolb C: Boundaries in development: formation and function. Annu Rev Cell Dev Biol 2001, 17:189-214.

56. Martin AC, Wieschaus EF: Tensions divide. Nat Cell Biol 2010, 12:5-7.

57. McNeill H: Sticking together and sorting things out: adhesion as a force in development. Nat Rev Genet 2000, 1:100-108.

58. Monier B, Pelissier-Monier A, Sanson B: Establishment and maintenance of compartmental boundaries: role of contractile actomyosin barriers. Cell Mol Life Sci 2011, 68:1897-1910

59. Vincent JP, Irons D: Developmental biology: tension at the border. Curr Biol 2009, 19:R1028-R1030

60. Wang S, Tulina N, Carlin DL, Rulifson EJ: The origin of islet-like cells in Drosophila identifies parallels to the vertebrate endocrine axis. Proc Nat Acad Sci U S A 2007, 104:19873-19878.

61. Evans CJ, Olson JM, Ngo KT, Kim E, Lee NE, Kuoy E, Patananan AN, Sitz D, Tran P, Do MT, Yackle K, Cespedes A, Hartenstein V, Call GB, Banerjee U: G-TRACE: rapid Gal4-based cell lineage analysis in Drosophila. Nat Methods 2009, 6:603-605.

62. Erclik T, Hartenstein V, Lipshitz HD, McInnes RR: Conserved role of the Vsx genes supports a monophyletic origin for bilaterian visual systems. Curr Biol 2008, 18:1278-1287.

63. Burmeister M, Novak J, Liang MY, Basu S, Ploder L, Hawes NL, Vidgen D, Hoover F, Goldman D, Kalnins VI, Roderick TH, Taylor BA, Hankin MH, McInnes RR: Ocular retardation mouse caused by Chx10 homeobox null allele: impaired retinal progenitor proliferation and bipolar cell differentiation. Nat Genet 1996, 12:376-384.

64. Muthuswamy SK, Xue B: Cell polarity as a regulator of cancer cell behavior plasticity. Annu Rev Cell Dev Biol 2012, 28:599-625.

65. Perez-Pomares JM, Foty RA: Tissue fusion and cell sorting in embryonic development and disease: biomedical implications. Bioessays 2006 28:809-821

66. Badouel C, Garg A, McNeill H: Herding Hippos: regulating growth in flies and man. Curr Opin Cell Biol 2009, 21:837-843.

67. Halder G, Johnson RL: Hippo signaling: growth control and beyond Development 2011, 138:9-22.

68. Reddy BV, Irvine KD: The Fat and Warts signaling pathways: new insights into their regulation, mechanism and conservation. Development 2008 135:2827-2838.

69. Kawamori H, Tai M, Sato M, Yasugi T, Tabata T: Fat/Hippo pathway regulates the progress of neural differentiation signaling in the Drosophila optic lobe. Dev Growth Differ 2011, 53:653-667.

70. Clark HF, Brentrup D, Schneitz K, Bieber A, Goodman C, Noll M: Dachsous encodes a member of the cadherin superfamily that controls imaginal disc morphogenesis in Drosophila. Genes Dev 1995, 9:1530-1542.

71. Matakatsu H, Blair SS: Interactions between Fat and Dachsous and the regulation of planar cell polarity in the Drosophila wing. Development 2004, 131:3785-3794.
72. Sopko R, Silva E, Clayton L, Gardano L, Barrios-Rodiles M, Wrana J, Varelas X, Arbouzova NI, Shaw S, Saburi S, Matakatsu H, Blair S, McNeill H: Phosphorylation of the tumor suppressor fat is regulated by its ligand Dachsous and the kinase discs overgrown. Curr Biol 2009, 19:1112-1117

73. Willecke M, Hamaratoglu F, Sansores-Garcia L, Tao C, Halder G: Boundaries of Dachsous Cadherin activity modulate the Hippo signaling pathway to induce cell proliferation. Proc Natl Acad Sci U S A 2008, 105:14897-14902.

74. Lee T, Luo L: Mosaic analysis with a repressible cell marker for studies of gene function in neuronal morphogenesis. Neuron 1999, 22:451-461.

75. Hay BA, Wolff T, Rubin GM: Expression of baculovirus P35 prevents cell death in Drosophila. Development 1994, 120:2121-2129.

76. Wei SY, Escudero LM, Yu F, Chang LH, Chen LY, Ho YH, Lin CM, Chou CS, Chia W, Modolell J, Hsu JC: Echinoid is a component of adherens junctions that cooperates with DE-Cadherin to mediate cell adhesion. Dev Cell 2005, 8:493-504

77. Le Borgne R, Bellaiche $\mathrm{Y}$, Schweisguth F: Drosophila E-cadherin regulates the orientation of asymmetric cell division in the sensory organ lineage. Curr Biol 2002, 12:95-104

78. Oda H, Uemura T, Harada Y, Iwai Y, Takeichi M: A Drosophila homolog of cadherin associated with armadillo and essential for embryonic cell-cell adhesion. Dev Biol 1994, 165:716-726.

79. Tepass U, Gruszynski-DeFeo E, Haag TA, Omatyar L, Torok T, Hartenstein V: Shotgun encodes Drosophila E-cadherin and is preferentially required during cell rearrangement in the neurectoderm and other morphogenetically active epithelia. Genes Dev 1996, 10:672-685.

80. Uemura T, Oda H, Kraut R, Hayashi S, Kotaoka Y, Takeichi M: Zygotic Drosophila E-cadherin expression is required for processes of dynamic epithelial cell rearrangement in the Drosophila embryo. Genes Dev 1996, 10:659-671.

81. Wang F, Dumstrei $K$, Haag T, Hartenstein V: The role of DE-cadherin during cellularization, germ layer formation and early neurogenesis in the Drosophila embryo. Dev Biol 2004, 270:350-363.

82. Oda $\mathrm{H}$, Takeichi M: Evolution: structural and functional diversity of cadherin at the adherens junction. J Cell Biol 2011, 193:1137-1146.

83. Rujano MA, Sanchez-Pulido L, Pennetier C, le Dez G, Basto R: The microcephaly protein Asp regulates neuroepithelium morphogenesis by controlling the spatial distribution of myosin II. Nat Cell Biol 2013, 15:1294-1306

84. Inoue T, Tanaka T, Takeichi M, Chisaka O, Nakamura S, Osumi N: Role of cadherins in maintaining the compartment boundary between the cortex and striatum during development. Development 2001, 128:561-569.

85. Fung S, Wang F, Chase M, Godt D, Hartenstein V: Expression profile of the cadherin family in the developing Drosophila brain. J Comp Neurol 2008 506:469-488.

86. Garcia-Bellido A, Santamaria P: Developmental analysis of the wing disc in the mutant engrailed of Drosophila melanogaster. Genetics 1972, 72:87-104.

87. Kornberg T: Engrailed: a gene controlling compartment and segment formation in Drosophila. Proc Natl Acad Sci U S A 1981, 78:1095-1099.

88. Lawrence PA, Morata G: Compartments in the wing of Drosophila: a study of the engrailed gene. Dev Biol 1976, 50:321-337.

89. Morata G, Lawrence PA: Control of compartment development by the engrailed gene in Drosophila. Nature 1975, 255:614-617.

90. Fischbach KF, Dittrich APM: The optic lobe of Drosophila melanogaster. I. A Golgi analysis of wild-type structure. Cell Tissue Res 1989, 258:441-475.

91. Morante J, Desplan C: The color-vision circuit in the medulla of Drosophila. Curr Biol 2008, 18:553-565.

92. Li X, Erclik T, Bertet C, Chen Z, Voutev R, Venkatesh S, Morante J, Celik A, Desplan C: Temporal patterning of Drosophila medulla neuroblasts controls neural fates. Nature 2013, 498:456-462.

93. Suzuki T, Kaido M, Takayama R, Sato M: A temporal mechanism that produces neuronal diversity in the Drosophila visual center. Dev Biol 2013, 380:12-24

94. Baumgardt M, Karlsson D, Terriente J, Diaz-Benjumea FJ, Thor S: Neuronal subtype specification within a lineage by opposing temporal feedforward loops. Cell 2009, 139:969-982.

95. Brody T, Odenwald WF: Programmed transformations in neuroblast gene expression during Drosophila CNS lineage development. Dev Biol 2000, 226:34-44. 
96. Cleary MD, Doe CQ: Regulation of neuroblast competence: multiple temporal identity factors specify distinct neuronal fates within a single early competence window. Genes Dev 2006, 20:429-434

97. Grosskortenhaus R, Pearson BJ, Marusich A, Doe CQ: Regulation of temporal identity transitions in Drosophila neuroblasts. Dev Cell 2005, 8:193-202.

98. Grosskortenhaus R, Robinson KJ, Doe CQ: Pdm and Castor specify lateborn motor neuron identity in the NB7-1 lineage. Genes Dev 2006, 20:2618-2627.

99. Isshiki T, Pearson B, Holbrook S, Doe CQ: Drosophila neuroblasts sequentially express transcription factors which specify the temporal identity of their neuronal progeny. Cell 2001, 106:511-521.

100. Kambadur R, Koizumi K, Stivers C, Nagle J, Poole SJ, Odenwald WF: Regulation of POU genes by castor and hunchback establishes layered compartments in the Drosophila CNS. Genes Dev 1998, $12: 246-260$

101. Lin S, Lee T: Generating neuronal diversity in the Drosophila central nervous system. Dev Dyn 2012, 241:57-68.

102. Mettler U, Vogler G, Urban J: Timing of identity: spatiotemporal regulation of hunchback in neuroblast lineages of Drosophila by Seven-up and Prospero. Development 2006, 133:429-437.

103. Novotny $T$, Eiselt R, Urban J: Hunchback is required for the specification of the early sublineage of neuroblast 7-3 in the Drosophila central nervous system. Development 2002, 129:1027-1036.

104. Pearson BJ, Doe CQ: Regulation of neuroblast competence in Drosophila. Nature 2003, 425:624-628.

105. Tran KD, Doe CQ: Pdm and Castor close successive temporal identity windows in the NB3-1 lineage. Development 2008, 135:3491-3499.

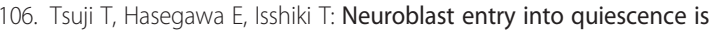
regulated intrinsically by the combined action of spatial Hox proteins and temporal identity factors. Development 2008, 135:3859-3869.

107. Li X, Chen Z, Desplan C: Temporal patterning of neural progenitors in Drosophila. Curr Top Dev Biol 2013, 105:69-96.

108. Wang W, Li Y, Zhou L, Yue H, Luo H: Role of JAK/STAT signaling in neuroepithelial stem cell maintenance and proliferation in the Drosophila optic lobe. Biochem Biophys Res Commun 2011, 410:714-720.

109. Yasugi T, Umetsu D, Murakami S, Sato M, Tabata T: Drosophila optic lobe neuroblasts triggered by a wave of proneural gene expression that is negatively regulated by JAK/STAT. Development 2008, 135:1471-1480.

110. Hayden MA, Akong K, Peifer M: Novel roles for APC family members and Wingless/Wnt signaling during Drosophila brain development. Dev Biol 2007, 305:358-376

111. Kozmik Z, Holland ND, Kreslova J, Oliveri D, Schubert M, Jonasova K, Holland LZ, Pestarino M, Benes V, Candiani S: Pax-Six-Eya-Dach network during amphioxus development: conservation in vitro but context specificity in vivo. Dev Biol 2007, 306:143-159.

112. Lowe CJ, Wu M, Salic A, Evans L, Lander E, Stange-Thomann N, Gruber CE, Gerhart J, Kirschner M: Anteroposterior patterning in hemichordates and the origins of the chordate nervous system. Cell 2003, 113:853-865.

113. Oliver G, Mailhos A, Wehr R, Copeland NG, Jenkins NA, Gruss P: Six3, a murine homologue of the sine oculis gene, demarcates the most anterior border of the developing neural plate and is expressed during eye development. Development 1995, 121:4045-4055.

114. Posnien N, Schinko J, Grossmann D, Shippy TD, Konopova B, Bucher G: RNAi in the red flour beetle (Tribolium). Cold Spring Harb Protoc 2009 doi:10.1101/pdb.prot5256.

115. Poustka AJ, Kuhn A, Groth D, Weise V, Yaguchi S, Burke RD, Herwig R, Lehrach H, Panopoulou G: A global view of gene expression in lithium and zinc treated sea urchin embryos: new components of gene regulatory networks. Genome Biol 2007, 8:R85

116. Santagata S, Resh C, Hejnol A, Martindale MQ, Passamaneck YJ: Development of the larval anterior neurogenic domains of Terebratalia transversa (Brachiopoda) provides insights into the diversification of larval apical organs and the spiralian nervous system. EvoDevo 2012, 3:3

117. Seo HC, Curtiss J, Mlodzik M, Fjose A: Six class homeobox genes in Drosophila belong to three distinct families and are involved in head development. Mech Dev 1999, 83:127-139.

118. Sinigaglia C, Busengdal $H$, Leclere $L$, Technau U, Rentzsch F: The bilaterian head patterning gene six3/6 controls aboral domain development in a cnidarian. PLOS Biol 2013, 11:e1001488.
119. Steinmetz PR, Urbach R, Posnien N, Eriksson J, Kostyuchenko RP, Brena C, Guy K, Akam M, Bucher G, Arendt D: Six3 demarcates the anterior-most developing brain region in bilaterian animals. EvoDevo 2010, 1:14.

120. Wei Z, Yaguchi J, Yaguchi S, Angerer RC, Angerer LM: The sea urchin animal pole domain is a Six3-dependent neurogenic patterning center. Development 2009, 136:1179-1189.

121. Zhou X, Hollemann T, Pieler T, Gruss P: Cloning and expression of xSix3, the Xenopus homologue of murine Six3. Mech Dev 2000, 91:327-330.

122. Christensen KL, Patrick AN, McCoy EL, Ford HL: The six family of homeobox genes in development and cancer. Adv Cancer Res 2008, 101:93-126

123. Li X, Perissi V, Liu F, Rose DW, Rosenfeld MG: Tissue-specific regulation of retinal and pituitary precursor cell proliferation. Science 2002, 297:1180-1183.

124. Lagutin OV, Zhu CC, Kobayashi D, Topczewski J, Shimamura K, Puelles L, Russell HR, McKinnon PJ, Solnica-Krezel L, Oliver G: Six3 repression of Wnt signaling in the anterior neuroectoderm is essential for vertebrate forebrain development. Genes Dev 2003, 17:368-379.

125. Aldahmesh MA, Khan AO, Hijazi H, Alkuraya FS: Homozygous truncation of SIX6 causes complex microphthalmia in humans. Clin Genet 2013, 84:198-199.

126. Gallardo ME, Lopez-Rios J, Fernaud-Espinosa I, Granadino B, Sanz R, Ramos C, Ayuso C, Seller MJ, Brunner HG, Bovolenta P, de Rodriguez Cordoba S: Genomic cloning and characterization of the human homeobox gene SIX6 reveals a cluster of SIX genes in chromosome 14 and associates SIX6 hemizygosity with bilateral anophthalmia and pituitary anomalies. Genomics 1999, 61:82-91.

127. Gallardo ME, De Rodriguez Cordoba S, Schneider AS, Dwyer MA, Ayuso C, Bovolenta P: Analysis of the developmental SIX6 homeobox gene in patients with anophthalmia/microphthalmia. Am J Med Genet A 2004, 129A:92-94

128. Geng X, Speirs C, Lagutin O, Inbal A, Liu W, Solnica-Krezel L, Jeong $Y$, Epstein DJ, Oliver G: Haploinsufficiency of Six3 fails to activate Sonic hedgehog expression in the ventral forebrain and causes holoprosencephaly. Dev Cell 2008, 15:236-247.

129. Lacbawan F, Solomon BD, Roessler E, El-Jaick K, Domene S, Velez Jl, Zhou N, Hadley D, Balog JZ, Long R, Fryer A, Smith W, Omar S, McLean SD, Clarkson K, Lichty A, Clegg NJ, Delgado MR, Levey E, Stashinko E, Potocki L, Vanallen MI, Clayton-Smith J, Donnai D, Bianchi DW, Juliusson PB, Njolstad PR, Brunner HG, Carey JG, Hehr U, et al: Clinical spectrum of SIX3-associated mutations in holoprosencephaly: correlation between genotype, phenotype and function. J Med Genet 2009, 46:389-398.

130. Laflamme C, Filion C, Labelle Y: Functional characterization of SIX3 homeodomain mutations in holoprosencephaly: interaction with the nuclear receptor NR4A3/NOR1. Hum Mutat 2004, 24:502-508.

131. Pasquier L, Dubourg C, Blayau M, Lazaro L, Le Marec B, David V, Odent S: A new mutation in the six-domain of SIX3 gene causes holoprosencephaly. Eur J Hum Genet 2000, 8:797-800.

132. Pasquier L, Dubourg C, Gonzales M, Lazaro L, David V, Odent S, Encha-Razavi F: First occurrence of aprosencephaly/atelencephaly and holoprosencephaly in a family with a SIX3 gene mutation and phenotype/genotype correlation in our series of SIX3 mutations. J Med Genet 2005, 42:e4.

133. Rauchman M, Hoffman WH, Hanna JD, Kulharya AS, Figueroa RE, Yang J, Tuck-Miller CM: Exclusion of SIX6 hemizygosity in a child with anophthalmia, panhypopituitarism and renal failure. Am J Med Genet 2001, 104:31-36.

134. Ribeiro LA, El-Jaick KB, Muenke M, Richieri-Costa A: SIX3 mutations with holoprosencephaly. Am J Med Genet A 2006, 140:2577-2583.

135. Solomon BD, Lacbawan F, Jain M, Domene S, Roessler E, Moore C, Dobyns WB, Muenke M: A novel SIX3 mutation segregates with holoprosencephaly in a large family. Am J Med Genet A 2009, 149A:919-925.

136. Manseau L, Baradaran A, Brower D, Budhu A, Elefant F, Phan H, Philp AV, Yang M, Glover D, Kaiser K, Palter K, Selleck S: GAL4 enhancer traps expressed in the embryo, larval brain, imaginal discs, and ovary of Drosophila. Dev Dyn 1997, 209:310-322.

137. McGuire SE, Le PT, Osborn AJ, Matsumoto K, Davis RL: Spatiotemporal rescue of memory dysfunction in Drosophila. Science 2003, 302:1765-1768.

138. Luo L, Liao YJ, Jan LY, Jan YN: Distinct morphogenetic functions of similar small GTPases: Drosophila Drac1 is involved in axonal outgrowth and myoblast fusion. Genes Dev 1994, 8:1787-1802. 
139. Gonzalez-Reyes A, St Johnston D: The Drosophila AP axis is polarised by the cadherin-mediated positioning of the oocyte. Development 1998 125:3635-3644.

140. Gerlitz O, Basler K: Wingful, an extracellular feedback inhibitor of Wingless. Genes Dev 2002, 16:1055-1059.

141. Staehling-Hampton K, Jackson PD, Clark MJ, Brand AH, Hoffmann FM: Specificity of bone morphogenetic protein-related factors: cell fate and gene expression changes in Drosophila embryos induced by decapentaplegic but not 60A. Cell Growth Differ 1994, 5:585-593.

142. Kenyon KL, Li DJ, Clouser C, Tran S, Pignoni F: Fly SIX-type homeodomain proteins Sine oculis and Optix partner with different cofactors during eye development. Dev Dyn 2005, 234:497-504.

143. Rawlins EL, Lovegrove B, Jarman AP: Echinoid facilitates Notch pathway signalling during Drosophila neurogenesis through functional interaction with Delta. Development 2003, 130:6475-6484.

144. Zhou W, Hong Y: Drosophila Patj plays a supporting role in apical-basal polarity but is essential for viability. Development 2012, 139:2891-2896.

145. Albertson R, Doe CQ: Dlg, Scrib and Lgl regulate neuroblast cell size and mitotic spindle asymmetry. Nat Cell Biol 2003, 5:166-170.

146. Schindelin J, Arganda-Carreras I, Frise E, Kaynig V, Longair M, Pietzsch T, Preibisch S, Rueden C, Saalfeld S, Schmid B, Tinevez JY, White DJ,

Hartenstein V, Eliceiri K, Tomancak P, Cardona A: Fiji: an open-source platform for biological-image analysis. Nat Methods 2012, 9:676-682.

doi:10.1186/1749-8104-9-18

Cite this article as: Gold and Brand: Optix defines a neuroepithelial compartment in the optic lobe of the Drosophila brain. Neural Development 2014 9:18.

\section{Submit your next manuscript to BioMed Central and take full advantage of:}

- Convenient online submission

- Thorough peer review

- No space constraints or color figure charges

- Immediate publication on acceptance

- Inclusion in PubMed, CAS, Scopus and Google Scholar

- Research which is freely available for redistribution 